\title{
Nanocrystalline materials studied by powder diffraction line profile analysis
}

\author{
Tamás Ungár* and Jenő Gubicza \\ Department of Materials Physics, Institute of Physics of the Eötvös University Budapest, P.O. Box 32, 1518 Budapest, Hungary
}

Received January 31, 2006; accepted July 21, 2006

X-ray powder diffraction / Line profile analysis / Nanocrystals / Crystallite size / Subgrains / Microstrain / Dislocations / Slip systems

\begin{abstract}
X-ray powder diffraction is a powerful tool for characterising the microstructure of crystalline materials in terms of size and strain. It is widely applied for nanocrystalline materials, especially since other methods, in particular electron microscopy is, on the one hand tedious and time consuming, on the other hand, due to the often metastable states of nanomaterials it might change their microstructures. It is attempted to overview the applications of microstructure characterization by powder diffraction on nanocrystalline metals, alloys, ceramics and carbon base materials. Whenever opportunity is given, the data provided by the X-ray method are compared and discussed together with results of electron microscopy. Since the topic is vast we do not try to cover the entire field.
\end{abstract}

\section{Introduction}

X-ray line profile analysis (XLPA) is a well established and widely acknowledged powerful method for characterizing the microstructure of crystalline materials. Together with the other major characterization methods, especially transmission and scanning electron microscopy (TEM and SEM), and the different atomic resolution methods, in particular scanning tunneling and atomic force microscopy (STM and AFM), XLPA provides additional microstructure properties, like e.g. average crystallite size and size distribution, average dislocation density and dislocation character, slip activity and planar defect density, or different types of internal stresses. In nanocrystalline materials the crystallite or grain size is extremely small and the defect density can be very high, therefore the electron microscopy and atomic resolution methods encounter experimental difficulties or even fail to characterize the microstructure. In such cases XLPA becomes almost the only method for characterizing microstructures. The microstructure of nanomaterials is as various as nanomaterials themselves. They can either be in the form of loose pow-

* Correspondence author (e-mail: ungar@ludens.elte.hu) ders or compact bulk materials, ceramics, ionic crystals or metals and they can have been produced by different methods, like inert gas condensation and compaction [1, 2], ball milling [3], thermal plasma synthesis, cf. [4], chemical methods using precursors $[5,6]$ or severe plastic deformation, as for example equal channel angular pressing (ECAP) [7, 8] or high pressure torsion (HPT) [8, 9]. The microstructure of this type of materials can be devided into two fundamental features: (i) the grain size and (ii) the structure of lattice defects.

The ideal powder diffraction pattern consists of narrow, symmetrical, delta-function like peaks at the exact Bragg positions. The analysis of the deviations from the ideal powder pattern is X-ray line profile analysis. A number of different types of deviations are conceivable. In terms of peak profiles at least the following fundamental features can be observed: (a) peak shifts, $(b)$ peak broadening, $(c)$ peak asymmetries and $(d)$ anisotropic broadening or peak shape. Microstructure properties can be summarised at least into the following different categories: (1) internal stresses, (2) stress gradients, (3) stacking faults, (4) twinning, (5) crystallite or grain smallness, (6) microstresses of differen types, (7) long-range internal stresses, (8) chemical heterogeneities, (9) chemical gradients, (10) anisotropic crystallite shape or (11) anisotropic strain. There is no one-to-one correlation between the different peak profile features and the different microstructural properties. For example (i) peak shift can be related to internal stresses, chemical gradients or planar faults, especially stacking faults or twinning, (ii) peak broadening can indicate crystallite smallness and microstresses, however, stress gradients and/or chemical heterogeneities can also cause peak broadening, (iii) peak asymmetries can be caused by longrange internal stresses, planar faults or chemical heterogeneities, and (iv) anisotropic peak broadening can result from anisotropic crystallite shape, anisotropic strain or planar defects. Table 1 is an attempt to summarise the correlation between peak profile features and microstructure elements. Obviously, the interpretation of powder patterns in terms of microstructure properties becomes more reliable if other methods, especially TEM and/or SEM, are also used. On the other hand, the results of other methods, in particular TEM or SEM, can be refined and/or complemented by using XLPA. 
Table 1. Correlations between peak profile features, i.e. broadening, shifts, asymmetries or shape, and the different microstructure elements.

\begin{tabular}{|c|c|c|c|c|c|}
\hline $\begin{array}{l}\text { Peak Profile Features // } \\
\text { // Microstructure Properties }\end{array}$ & Peak Shift & Peak Broadening & Peak Asymmetry & $\begin{array}{l}\text { Anisotropic } \\
\text { Peak Broadening }\end{array}$ & Peak Shape \\
\hline Dislocations & & + & + & + & + \\
\hline Twinning & & + & + & + & + \\
\hline Microstresses & & + & & & \\
\hline $\begin{array}{l}\text { Long-Range Internal Stresses } \\
\text { or Stress Gradients }\end{array}$ & + & & + & + & \\
\hline Grain Boundaries & + & + & & & \\
\hline Sub-Boundaries & + & + & & & \\
\hline Internal Stresses & + & & & & \\
\hline Coherency Strains & + & + & + & + & \\
\hline $\begin{array}{c}\text { Chemical Heterogeneities } \\
\text { or Chemical Gradients }\end{array}$ & + & + & + & & \\
\hline Precipitates and Inclusions & + & & + & & + \\
\hline $\begin{array}{l}\text { Crystallite or Grain Smallness } \\
\text { or Subgrains }\end{array}$ & & + & & + & + \\
\hline
\end{tabular}

The microstructure properties from (1) to (11) have been treated on well established physical basis. Internal stresses and their effect on powder patterns are described by the elastic properties of crystals $[10,11]$. The effect of stacking faults and twinning is worked out for cubic and hexagonal crystals [12-21]. Size broadening is treated in detail for spherical or non-spherical crystallites [22-29]. The effect of microstresses are worked out in detail for dislocations [28-38]. Asymmetric profiles corresponding to long-range internal stresses are related to the dipole polarization of dislocations [34, 35, 39, 40]. Chemical heterogeneities are a special feature in Ni-base $\gamma / \gamma^{\prime}$ superalloys which have been treated in terms of lattice mismatch [39-42]. Anisotropic crystallite shape are a delicate phenomenon [26] which has been treated by special elegance in the case of $\mathrm{ZnO}$ nanoparticles [23]. Finally, anisotropic strain broadening is a general feature of powder patterns [43-56], which is generally related to dislocations and the elastic properties of crystals. In the present work a few typical examples are reviewed where the microstructure of nanocrystalline materials has been characterized by the method of XLPA. In those cases, when the same material has been investigated by XLPA and also by other methods, especially TEM and SEM, a critical comparison and discussion of the results will be attempted.

\section{Metals and alloys}

\subsection{The microstructure of nanocrystalline metals synthesized by inert gas condensation and compaction}

Nanocrystalline Pd pellets were prepared by inert-gas condensation and subsequent compaction [57]. The 111/222 pair of X-ray diffraction peaks were evaluated by the classical Warren-Averbach method [12]. Good correlation was observed between the size distribution obtained from dark field TEM micrographs, see Fig. 1, and the size-distribution function provided by X-ray line profile analysis, see Fig. 2.

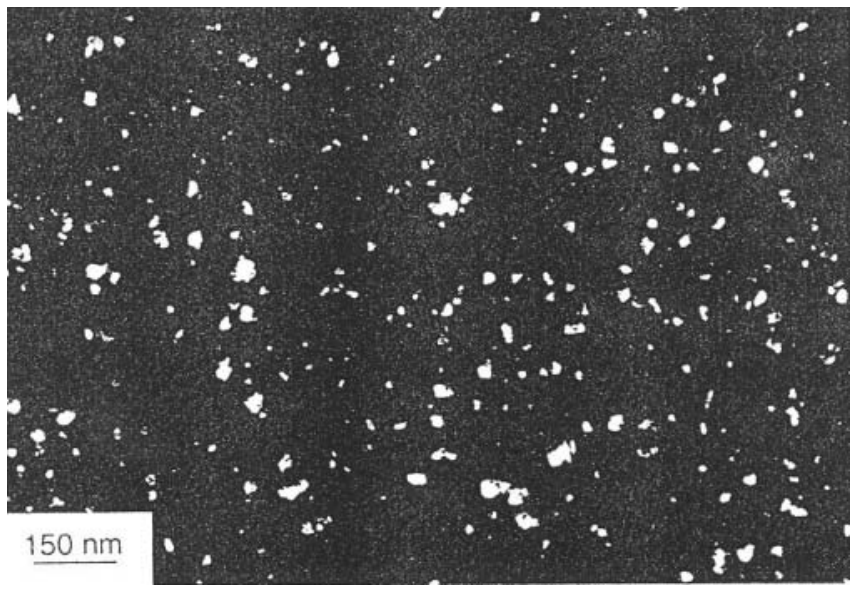

Fig. 1. Dark field TEM micrograph of ball milled and compacted nanocrystalline Pd (by courtesy from [57]). Several similar micrographs were evaluated to obtain the size distribution in Fig. 2.

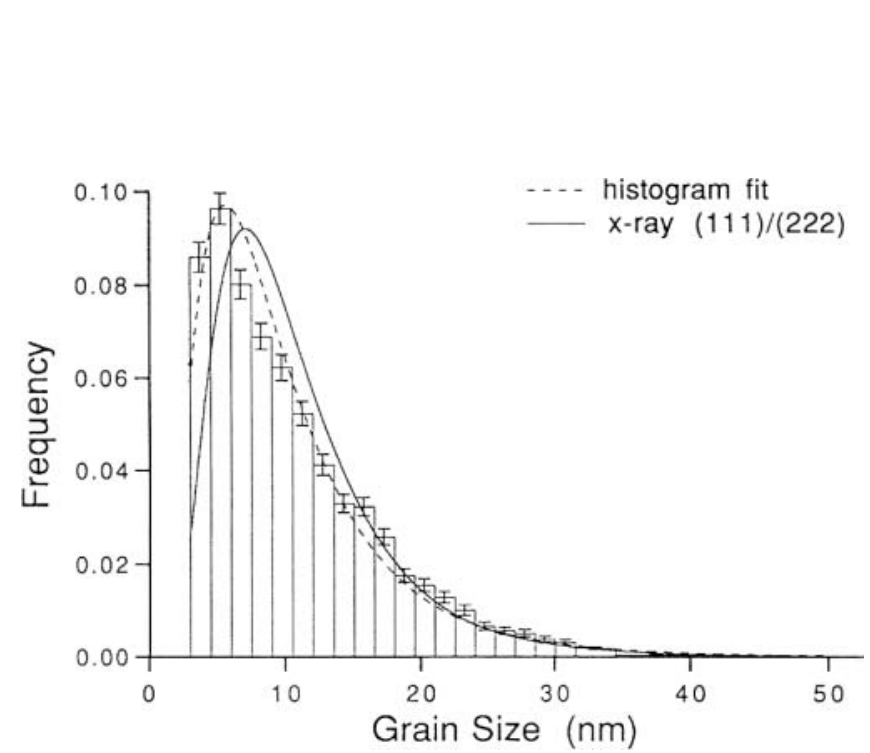

Fig. 2. Size distribution of crystallites in ball milled and compacted nanocrystalline Pd (by courtesy from [57]). The bar diagram and the solid line correspond to evaluation of TEM micrographs and X-ray line profiles, respectively. 


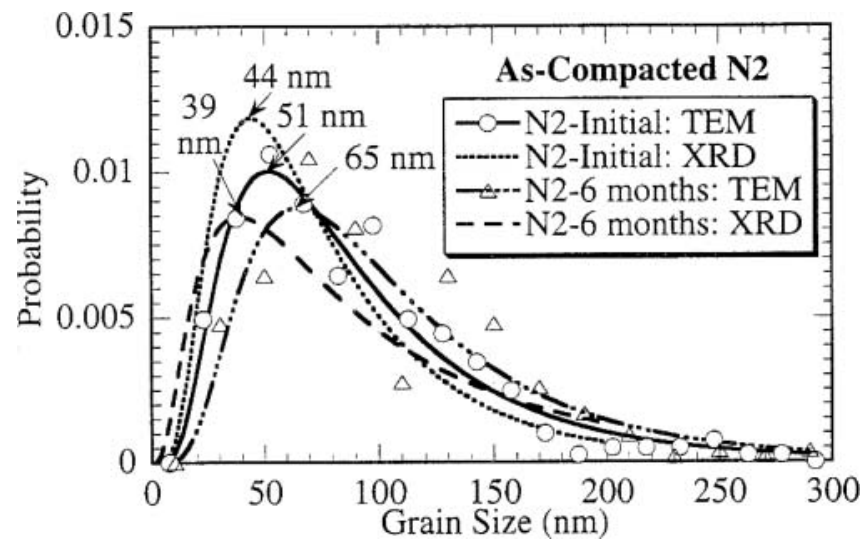

Fig. 3. Size distribution density functions of the grain size in inert gas condensed and compacted nanocrystalline coppes specimens (by courtesy from [59]).

Nanocrystalline $\mathrm{Cu}$ was produced by inert-gas condensation and subsequent hot compaction [2, 53, 58]. The crystallite size distribution functions of a specimen deformed up to about $10 \%$ strain was determined shortly after smaple preparation and after six months natural ageing at room temperature [59]. The log-normal size distribution functions determined either by TEM or by X-ray line profile analysis are shown in Fig. 3. The figure shows that grain size grows slightly during natural ageing at room temperature, and that TEM and X-ray size distributions are in good correlation.

\subsection{The microstructure of nanocrystalline metals produced by the method of ball milling}

The evolution of microstructure in nanocrystalline Ni powder during ball milling for up to $96 \mathrm{~h}$ was studied by X-ray line profile analysis by Scardi and Leoni [26]. The fitting of the measured powder pattern by the whole powder pattern modelling (WPPM) method [26] is shown in Fig. 4. Authors found that the dislocation density increased to a maximum value of about $2.4 \cdot 10^{16} \mathrm{~m}^{-2}$, and the mean crystallite size decreased to about $8 \mathrm{~nm}$ with milling time,

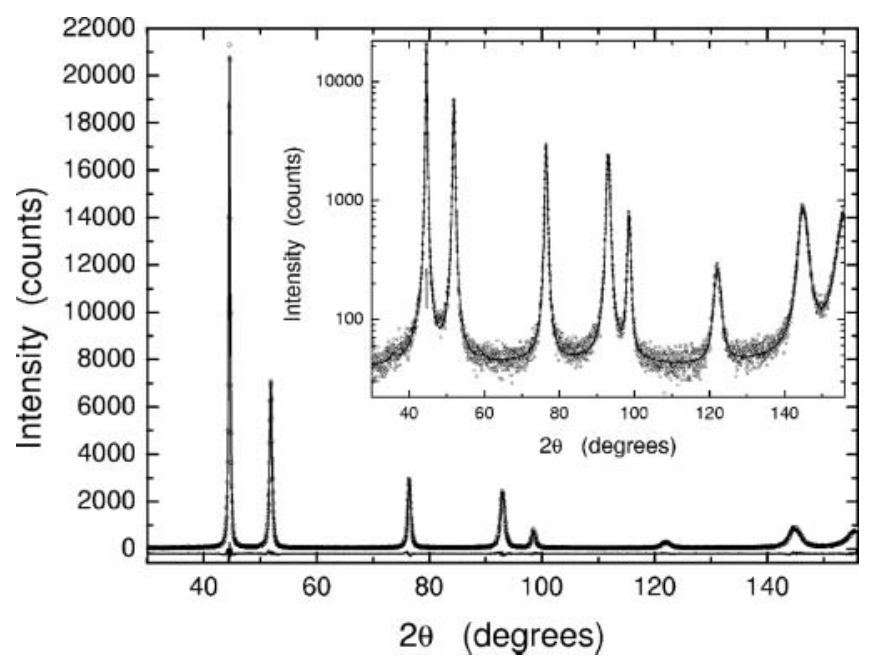

Fig. 4. Whole powder pattern modelling of nanocrystalline $\mathrm{Ni}$ samples ball-milled for $12 \mathrm{~h}$ (by courtesy from [26]). The open circles and the solid lines correspond to the measured data and the modelled curve obtained by the WPPM procedure, respectively [26]. however, the rates of increase or decrease slowed down with milling time. Stacking faults were produced in a low amount, while twin faults appeared after $12 \mathrm{~h}$ milling and their amount increased up to $3 \%$ after $96 \mathrm{~h}$ milling. The size distribution determined by X-ray diffraction and by TEM were in good agreement [26]. The saturation of the crystallite size and the root mean square strain was also observed in Fe powder subjected to low-energy vibratory ball milling, cf. [60, 61]. The steady-state crystallite size increases weakly with increasing milling temperature and decreases with increasing vibration amplitude. The root mean square strain varies linearly as the reciprocal value of the crystallite size [60].

The formation of nanostructure and mechanical alloying occur simultaneously if the powder mixture of two or more metallic elements are milled together. $\mathrm{Al}-\mathrm{Mg}$ alloys were produced by ball milling a mixture of $\mathrm{Al}$ and $\mathrm{Mg}$ powders [62]. X-ray line profile analysis revealed that with increasing nominal $\mathrm{Mg}$ content, or increasing milling time, the dislocation density increased and the character of dislocations was shifted toward edge type. These changes were attributed to the increase of the solute Mg concentration which increased the pinning effect of $\mathrm{Mg}$ atoms on edge dislocations, thus hindering their annihilation. After $3 \mathrm{~h}$ milling the $\mathrm{Mg}$ concentration in solid solution was much higher, about $5.6 \mathrm{wt} \%$, than the equilibrium solubility limit which is about $2 \mathrm{wt} \%$.

\subsection{The microstructure of nanocrystalline materials produced by the method of ball milling and hot isostatic pressure (HIP)}

Nanocrystalline tablets of pure copper and a $\mathrm{Li}-\mathrm{Mn}$ spinel were produced by hot isostatic pressure (HIP). The copper powder was produced by ball milling [16] whereas the $\mathrm{Li}-\mathrm{Mn}$ spinel powder was synthesized by reduction of oxides at high temperature [28]. In the whole powder pattern fitting it was found that the fit was poor when only a single $h k l$ independent mean square strain value was used. The best fit was obtained when both, dislocations and planar faults were included in the model of the microstructure. However, in the copper specimen the twinning probability was negligible and the stacking-fault contribution also small. The mean grain size was $41 \mathrm{~nm}$ and the dislocation density $1.4 \cdot 10^{15} \mathrm{~m}^{-2}$, in the order of magnitude of strongly deformed polycrystalline copper. For the $\mathrm{Li}-\mathrm{Mn}$ spinel, twinning had a considerable probability, and taking into account that the mean crystallite size was about $100 \mathrm{~nm}$, the observed twinning probability corresponded, on the average, to one twin fault in each crystallite. In the spinel powder the dislocation density was very low, about $9 \cdot 10^{13} \mathrm{~m}^{-2}$.

\subsection{The microstructure of nanocrystalline materials produced by electrodeposition}

Nanocrystalline gold films of thickness ranging from 30 to $190 \mathrm{~nm}$ were grown by thermal deposition on glass substrates [45]. The columnar, nanocrystalline grain structure was analysed by atomic force microscopy, TEM and XLPA. X-ray diffraction revealed a strong 111 texture to- 
gether with pronounced shape anisotropy of the crystallites. Besides size broadening, strong strain broadening was observed. The complex microstructure was solved in terms of dislocation densitites and Burgers vector determination. The modified Williamson-Hall plot was used to unfold the qualitative features of strain anisotropy in terms of dislocation occupation [45]. The analysis of the magnitude and anisotropy of the dislocation-induced line broadening with $h k l$ indicated that the dislocations have had a mixed screw/edge character with a tendency to form primarily on those slip planes running parallel to the substrate with densities of about $10^{15}$ to $10^{16} \mathrm{~m}^{-2}$.

Nanocrystalline, metallic copper, iron and platinum and various alloys were produced by pulsed electrodeposition [63-68]. The crystallite size distribution of the nanocrystalline copper was determined by TEM and XLPA [63]. Both methods showed a wide size distribution with the mean value of $15 \mathrm{~nm}$ and the variance of 1.5 . The graingrowth kinetics of nanocrystalline $\mathrm{Fe}$ was investigated in situ by synchrotron real-time X-ray diffraction during isothermal heat treatments at temperatures between 663 and $783 \mathrm{~K}$ [64]. Strain was expressed in terms of the meansquare-strain and the size distribution was assumed to be log-normal. Two regimes in the grain-growth were found: at lower temperatures, up to about $700 \mathrm{~K}$, the grain growth was smooth and moderate, the maximum was reached after $150 \mathrm{~min}$ at 50 to $100 \mathrm{~nm}$ depending on temperature. In this temperature range the size distribution remained narrow. At higher temperatures, between 700 and $783 \mathrm{~K}$, the grain growth was first rapid and later slower, reaching 150 to $100 \mathrm{~nm}$. In this temperature range the size distribution was broad. No evidence was found for the change in the type of the crystallite size distribution indicating normal grain growth. Nanocrystalline palladium was produced by pulsed electrochemical deposition and the variation of the crystallite size was studied as a function of the parameters of deposition, e.g. pulse length and pulsed current density [68]. The TEM grain size distribution followed the log-normal distribution function with the mean value about $20 \mathrm{~nm}$. The values provided by XLPA were somewhat smaller.

\subsection{The microstructure of submicron grain size metals produced by severe plastic deformations}

So called, severe plastic deformation (SPD) techniques are effective methods for producing bulk, porosity- and contamination-free ultrafine-grained (UFG) or nanostructured metals, cf. [7-9]. As the grain refinement during SPD processed metals occurs by the arrangement of dislocations into dislocation walls separating subgrains, the investigation of the dislocation structure is essential for understanding the evolution of fine-grained microstructure. The size and size-distribution of crystallites, grains, or subgrains, and the dislocation structure were studied intensively in different metals and alloys, e.g. Al [69], Al-alloys [69-71], $\mathrm{Cu}$ [72-78], or Ni [79-81], processed by SPD procedures at room temperature, e.g. by equal channel angular pressing (ECAP) or high pressure torsion (HPT). These two techniques are described in details elsewhere [8]. One pass of ECAP corresponds to an equivalent strain value of about 1 .
The imposed strain increases proportionally with the increase of the number of passes. It was found that the crystallite size decreased and the dislocation density increased with increasing strain for any studied metals. As an example the crystallite size and the dislocation density versus the imposed strain for $\mathrm{Al}-3 \% \mathrm{Mg}$ specimen is plotted in Fig. 5 [69]. As the deformation proceeds, the dislocation arrangement parameter, $M$ decreases indicating that dislocations are arranged into dipoles minimising the energy of their strain field $[70,71,73]$. This arrangement of dislocations is associated with the formation of dislocation walls resulting in the decrease of crystallite size. After room temperature SPD processes, the $q$ parameter is usually close to or less than the arithmetic mean of the theoretical values for pure edge and screw dislocations which indicates a more edge character of the dislocation structure, in accordance with cross-slip and easier annihilation of screw dislocations. The microstructure parameters of $\mathrm{Al}$ [69], $\mathrm{Al}-\mathrm{Mg}$ alloys [69], commercial $\mathrm{Al}-\mathrm{Mg}-\mathrm{Si}$ alloy (Al 6082) [71] and $\mathrm{Cu}$ [73] saturate after about 4 ECAP passes. This saturation was also observed after 3 revolutions of HPT for $\mathrm{Al}-\mathrm{Mg}-\mathrm{Sc}-\mathrm{Zr}$ alloy [70]. The saturation values correspond to the dynamic equilibrium between formation and annihilation of dislocations. The maximum dislocation density at room temperature for different metals are listed in Table 2. The combination of SPD procedures was applied to achieve further grain refinement in pure $\mathrm{Ni}$ $[80,81]$. HPT and cold rolling were applied on specimens processed by ECAP before. Additional deformation after ECAP resulted in further grain refinement and an increase of the dislocation density up to $25 \cdot 10^{14} \mathrm{~m}^{-2}$.

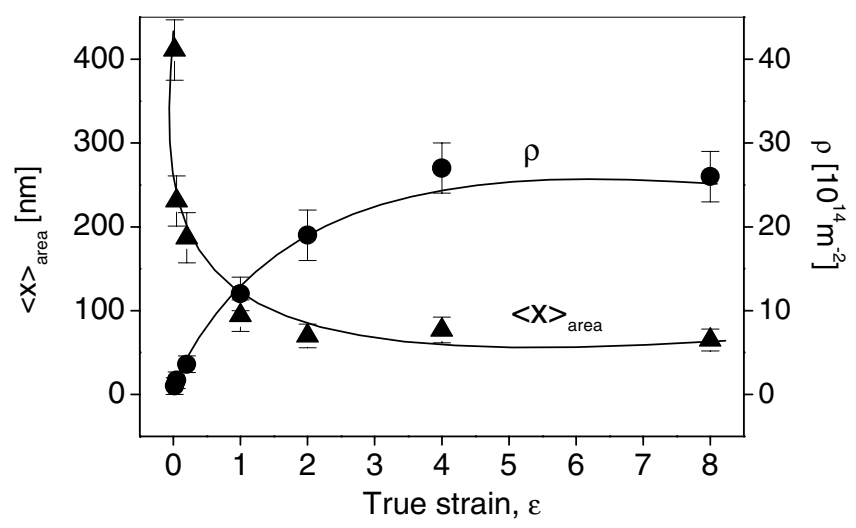

Fig. 5. The area-weighted mean crystallite size $\left(\langle x\rangle_{\text {area }}\right)$ and the dislocation density $(\rho)$ for $\mathrm{Al}-3 \mathrm{wt} \% \mathrm{Mg}$ processed by ECAP as a function of the imposed strain [69].

Table 2. The measured saturation values of the area-weighted mean crystallite size $\left(\langle x\rangle_{\text {area }}\right)$, the dislocation density $(\rho)$ for different f.c.c. metals processed by SPD methods. 8 ECAP and 6 HPT means 8 passes of Equal Channel Angular Pressing and 6 revolutions of High Pressure Torsion.

\begin{tabular}{lcc}
\hline Sample & $\langle x\rangle_{\text {area }}[\mathrm{nm}]$ & $\rho\left[10^{14} \mathrm{~m}^{-2}\right]$ \\
\hline $\mathrm{Al}, 8 \mathrm{ECAP}$ & $272 \pm 30$ & $1.8 \pm 0.3$ \\
$\mathrm{Al}-1 \% \mathrm{Mg}, 8$ ECAP & $88 \pm 10$ & $3.9 \pm 0.4$ \\
$\mathrm{Al}-3 \% \mathrm{Mg}, 8 \mathrm{ECAP}$ & $65 \pm 7$ & $23 \pm 2$ \\
$\mathrm{Cu}, 8$ ECAP & $64 \pm 7$ & $26 \pm 3$ \\
$\mathrm{Ni}, 8 \mathrm{ECAP}+6$ HPT & $48 \pm 6$ & $25 \pm 2$ \\
\hline
\end{tabular}


Submicron grain-size titanium was produced by ECAP and cold rolled subsequently [82]. The crystallite size distribution and the dislocation density and the type of active slip systems was studied by XLPA and TEM. The median and the variance of the crystallite size-distribution were obtained as: $m=39 \mathrm{~nm}$ and $\sigma=0.14$, respectively, providing the area weighted average crystallite size: $\langle x\rangle_{\text {area }}=$ $(41 \pm 3) \mathrm{nm}$. The average subgrain size determined by TEM was about $(45 \pm 5) \mathrm{nm}$, indicating that the X-ray size is equal to the subgrain size, as shown also by theoretical considerations in [83]. The average dislocation density was obtained to be $3 \cdot 10^{15} \mathrm{~m}^{-2}$ by XLPA. This extremely high value was confirmed by high resolution TEM (HREM) investigation [82].

\subsection{The microstructure of submicron grain size metals produced by crystallization from the amorphous phase}

The $\mathrm{Cu}_{60} \mathrm{Zr}_{30} \mathrm{Ti}_{10}$ alloy was quenched into the amorphous state [84]. HREM indicated that the as-quenched alloy consisted of homogeneously dispersed nanocrystals in the glassy matrix [84]. Authors showed that before heat treatments two metastable crystalline phases appeared prior to the precipitation of the $\mathrm{Cu}_{10} \mathrm{Zr}_{7}, \mathrm{Cu}_{8} \mathrm{Zr}_{3}$ and $\mathrm{Cu}_{3} \mathrm{Ti}_{2}$ equilibrium phases. Heat treatments were carried out according to the different exothermic peaks in the DSC heating curve. It was shown that after the first exothermic reaction, the nanometer-sized $\mathrm{CuZr}$ phase precipitated. In the second exothermic peak, the $\mathrm{CuZr}$ phase transformed to a metastable cubic phase, and finally, this metastable phase decomposed to equilibrium phases. Careful diffraction patterns were recorded in the as quenched (solid line in Fig. 6a) and the relaxed state (dotted line in Fig. 6a), relaxing heat treatment was carried out below the glass formation temperature at $753 \mathrm{~K}$. The difference of the two

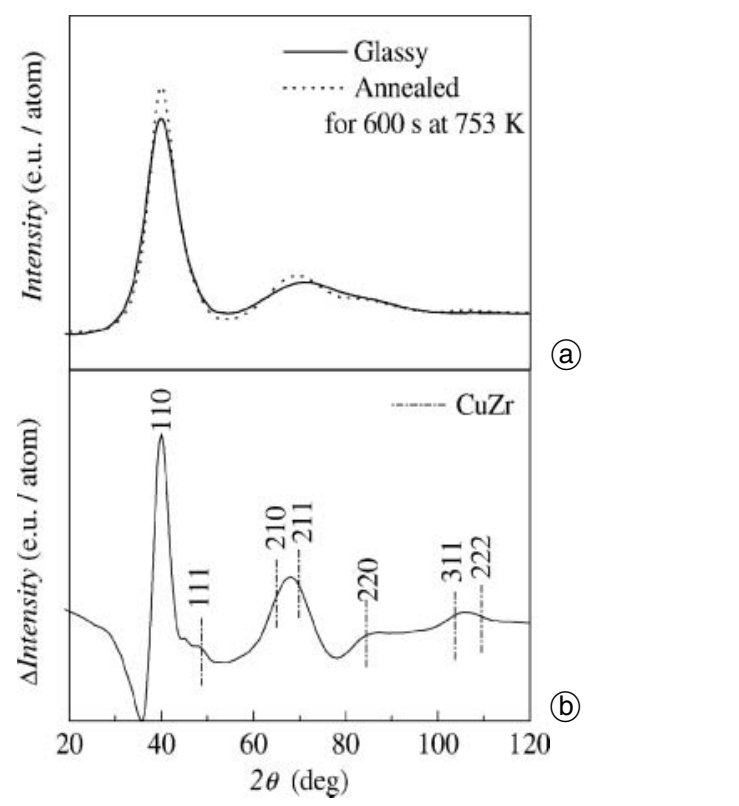

Fig. 6. (a) Powder patterns of the as quanched (solid line) and relaxed (dotted line) specimen of the $\mathrm{Cu}_{60} \mathrm{Zr}_{30} \mathrm{Ti}_{10}$ amorphous alloy (by courtesy from [84]). The specimen was relaxed after quenching at $753 \mathrm{~K}$ for $600 \mathrm{~s}$. (b) The difference between the powder patterns corresponding to the as quanched and relaxed states of the amorphous alloy [84]. diffraction patterns, shown in Fig. $6 \mathrm{~b}$ corresponds to the $\mathrm{CuZr}$ metastable cubic phase.

Nanocrystalline $\mathrm{HfNi}_{5}$ particles were produced by careful crystallization from the amorphous state [85]. The amorphous ribbons of $3 \mathrm{~mm}$ width and $11 \mu \mathrm{m}$ thickness were produced from a master alloy of $\mathrm{Hf}_{11} \mathrm{Ni}_{89}$ melted and fast quenched by the melt-spinning technique. The diffraction pattern, shown in Fig. 7, reveales a strong amorphous halo and well defined Debye-Scherrer rings indicating the coexistance of the amorphous and crystalline phases. The crystallite size-distribution function in Fig. 8, determined

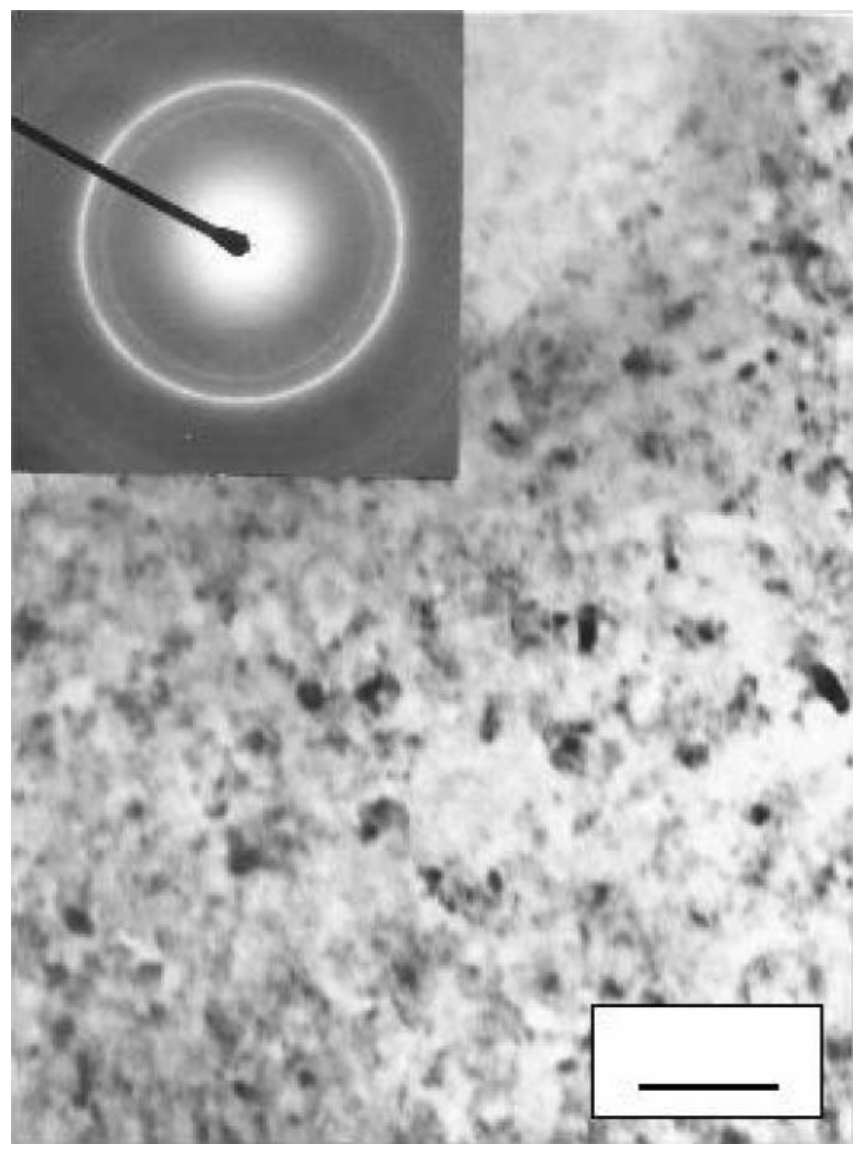

Fig. 7. TEM bright field micrograph of the as-quenched $\mathrm{Hf}_{11} \mathrm{Ni}_{89}$ alloy (by courtesy from [85]). The mark in the box corresponds to $100 \mathrm{~nm}$.

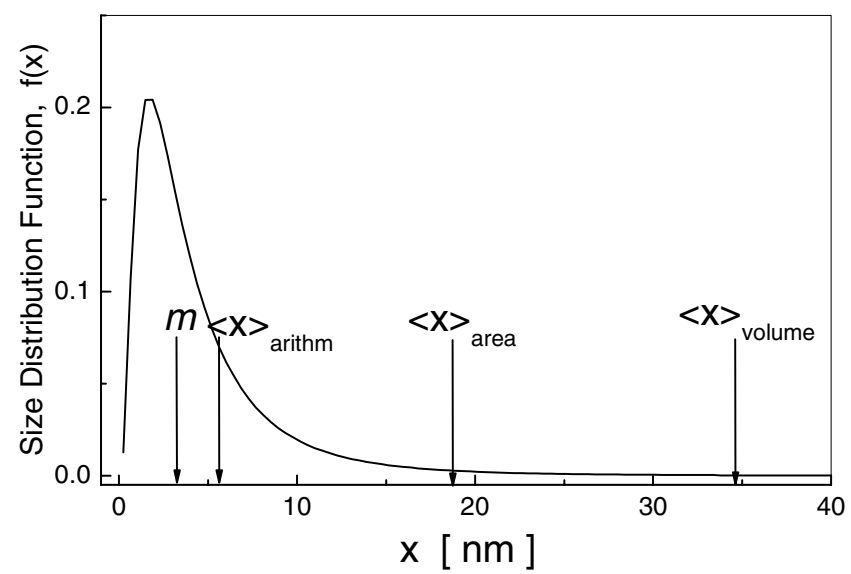

Fig. 8. The size-distribution density function, $f(x)$, of the crystallite size in the $\mathrm{HfNi}_{5}$ phase produced by fast quenching, determined by $\mathrm{X}$-ray line profile analysis (by courtesy from [85]). 
by XLPA, indicates a wide size distribution in good correlation with the TEM micrograph [85].

The nucleation and growth of nanocrystalline $\mathrm{Al}$ particles was observed during annealing the $\mathrm{Al}_{85} \mathrm{Ni}_{5} \mathrm{Y}_{8} \mathrm{Co}_{2}$ metallic glass well below the glass formation temperature, $T_{\mathrm{g}}$, by X-ray diffraction, differential scanning calorimetry, insitu electrical resistivity measurements and high-resolution transmission electron microscopy [86]. The nuclei of $\mathrm{Al}$ particles can be seen in the HREM micrographs in [86]. The authors found that, while the growth of the Al nuclei proceeds below $T_{\mathrm{g}}$, the crystallization of the amorphous matrix starts only above this temperature. The X-ray diffraction patterns in [86] indicate that only the Al particles are nanocrystalline, the particles of the crystallized phase grow very fast, passing through the nano-range within a narrow temperature window, as it can be seen in [86].

Nanocrystalline metallic $\mathrm{Ni}_{3} \mathrm{Fe}$ particles of about 10 to $15 \mathrm{~nm}$ were synthesized within a silica matrix by a sol-gel method [87]. The Rietveld powder structure refinement method was combined with the Warren-Averbach and modified Williamson-Hall procedures to determine the structure and microstructure. Lattice distortion was found to be in correlation with Mössbauer spectra. Other phases like, crystalline $\mathrm{SiO}_{2}$, traces of $\mathrm{Fe}_{2} \mathrm{SiO}_{4}$ and $\mathrm{NiO}$ were identified and characterized by XLPA. When the $\mathrm{SiO}_{2}$ content in the precursor gel increased from 50 to 90 at $\%$ the crystallite size of $\mathrm{Ni}_{3} \mathrm{Fe}$ particles decreased from 9.2 to $4.5 \mathrm{~nm}$ and the dislocation density increased from $5 \cdot 10^{15}$ to $40 \cdot 10^{15} \mathrm{~m}^{-2}$.

\subsection{Thermal stability of the microstructure of submicron grain size metals}

The thermal stability of the ultrafine-grained microstructure is an important issue from the point of view of the practical application of nanomaterials. The recovery of the dislocation structure and the recrystallization in SPD processed ultrafine-grained fcc metals was studied in [73, 75, 77, 88]. The dislocation density and the area-weighted mean crystallite size as a function of the temperature at the DSC curve for a specimen processed by 8 ECAP passes are shown in Fig. 9 [75]. At the temperature corre-

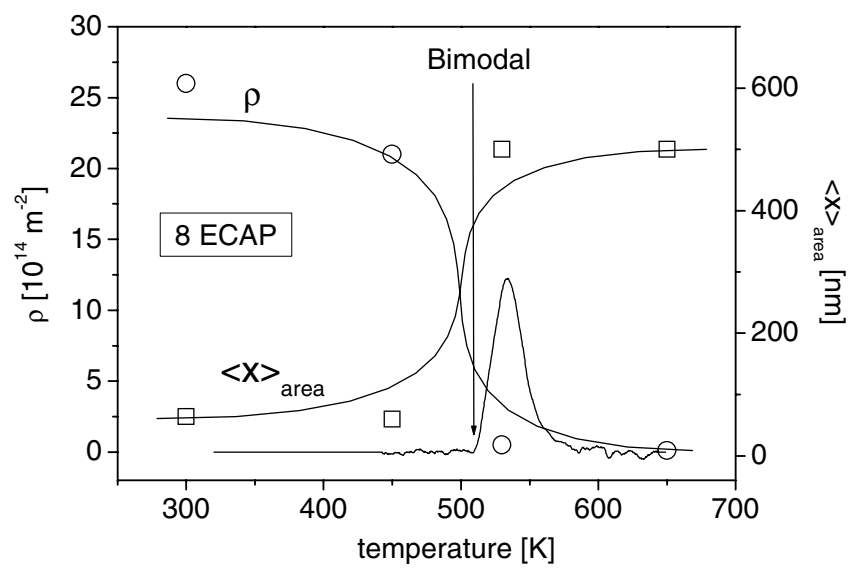

Fig. 9. The dislocation density and the area-weighted mean crystallite size as a function of temperature for $\mathrm{Cu}$ processed by 8 ECAP pass. The DSC trace obtained at $40 \mathrm{~K} / \mathrm{min}$ is also presented in the figure [75].

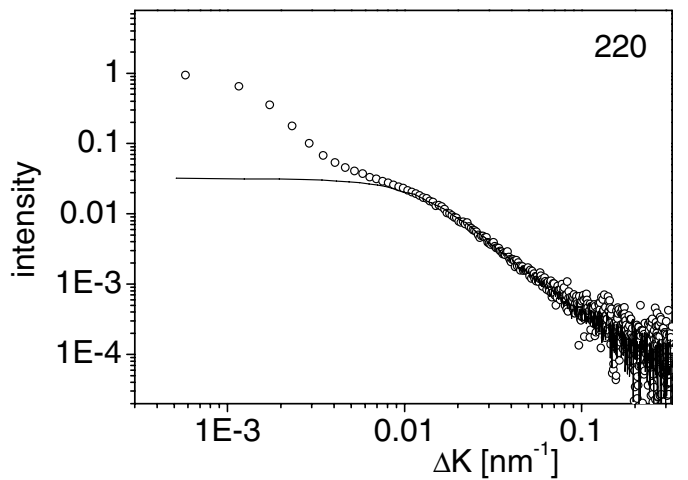

Fig. 10. The diffraction profiles of 220 reflections for the $\mathrm{Cu}$ specimen deformed by 8 ECAP passes (solid line) and after heat treatment at $500 \mathrm{~K}$ (open circles) in double logarithmic scale [75]. $\Delta K=2\left(\sin \Theta-\sin \Theta_{0}\right) / \lambda$ where $\Theta_{0}$ is the Bragg-angle and $\lambda$ is the wavelength of $\mathrm{X}$-rays.

sponding to the beginning of the DSC peak, each X-ray profile appears to be the sum of a narrow and a broad peak. This special shape of the diffraction lines was also observed by Kuzel et al., cf. [77] for copper samples deformed by HPT under $6 \mathrm{GPa}$ pressure and annealed at $523 \mathrm{k}$ for $100 \mathrm{~min}$. The bimodal structure was studied by TEM and was shown to have good ductility properties [89]. In Fig. 10 the circles represent the 220 peak for a specimen quenched from $500 \mathrm{~K}$ in double logarithmic scale. The figure shows that the intensity goes through a well defined inflection point at around $\Delta K \sim 0.006 \mathrm{~nm}^{-1}$ $\left(\Delta K=2\left(\sin \Theta-\sin \Theta_{0}\right) / \lambda\right.$ where $\Theta_{0}$ is the Bragg-angle and $\lambda$ is the wavelength of $\mathrm{X}$-rays), indicating that the diffraction profile consists of two peaks, indeed. The broad peak can be well approximated by the profile measured before the heat-treatment, suggesting that the this subprofile corresponds to the non-recovered regions of the material. The profile for the non annealed specimen (the solid line in Fig. 10) matches the tail part of the profile measured after annealing (open circles in Fig. 10). The difference between the solid line and the open circles gives a sharp peak corresponding to the recovered volume of the material. The other peaks of the specimen quenched from $500 \mathrm{~K}$ can be also decomposed into narrow and broad subprofiles. At the temperature corresponding to the maximum of the DSC peak, the mean crystallite size is about 8 times higher while the dislocation density 50 times lower than before annealing.

The thermal stability of submicron grain size Ti produced by the method of ECAP is demonstrated by Fig. 11 [73]. It can be seen that the dislocation density decreases monotonously up to the temperature of recrystallisation, about $860 \mathrm{~K}$, corresponding to the DSC exothermic peak, whereas the subgrain size remains stable up to about $800 \mathrm{~K}$ and increases rapidly above this temperature.

\subsection{The determination of active slip systems in hexagonal closed-packed crystals}

For polycrystalline hexagonal materials two characteristic parameters of the dislocation contrast factors, $q 1$ and $q 2$ are obtained from the evaluation of line profiles [90-92]. The values of $q 1$ and $q 2$ parameters are determined by the 


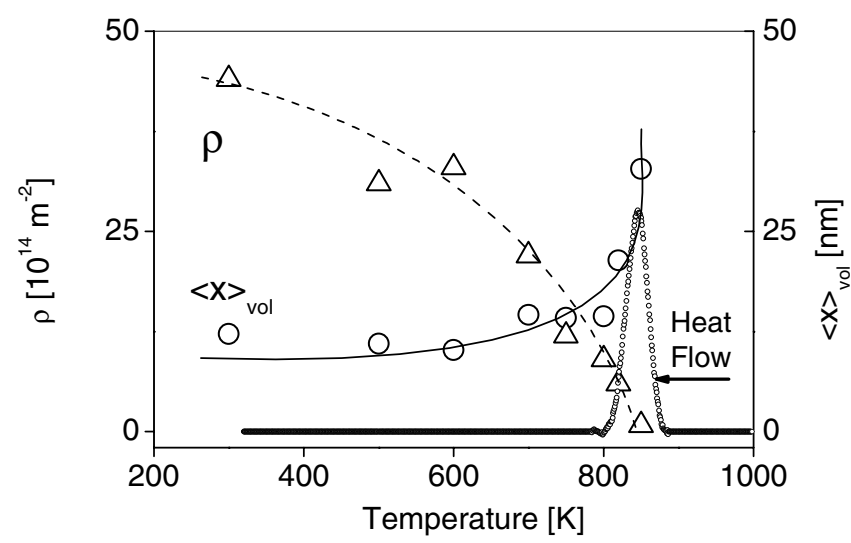

Fig. 11. Thermal stability of submicron grain size Ti produced by the method of ECAP (by courtesy from [59]). The small open circles are the DSC heating curve after subtracting the baseline. The large open circles and open up-triangles correspond to the volume average mean subgrain size and the average dislocation density, respectively [73].

elastic constants and the dislocation slip systems activated in the crystal. In hexagonal materials there are eleven dislocation slip systems. The momentum of the shortest lattice vector equals the a lattice parameter in the basal plane, therefore the directions of easy slip are the three $\langle a\rangle$-type directions. According to von Mises for plastic deformation of a polycrystalline material the activation of at least five independent slip systems is needed, therefore beside the three basal slip systems another dislocations should contribute to plastic flow. Moreover, the Burgersvectors of basal dislocations are perpendicular to the $c$ axis, therefore basal slips can not produce strain to the $c$ direction. Consequently, another non-basal slip systems with Burgers vectors having component parallel to the $c$ axis should be activated to deform hexagonal polycrystals. The prismatic and pyramidal slip systems and twinning are most probably required for plastic deformation of hexagonal polycrystals. As a consequence all the eleven slip systems in hexagonal materials should be taken into account in studying the dislocation structure. The eleven dislocation slip systems can be classified into three groups based on their Burgers vectors: $b_{1}=1 / 3\langle\overline{2} 110\rangle(\langle a\rangle$-type), $b_{2}=1 /{ }_{3}\langle 0001\rangle \quad(\langle c\rangle$-type $)$ and $b_{3}=1 / 3\langle 2113\rangle \quad(\langle c+a\rangle-$ type). There are 4,2 and 5 slip systems in the $\langle a\rangle,\langle c\rangle$ and $\langle c+a\rangle$ Burgers vector groups, respectively [47, 93]. A computer program was elaborated to determine the Burgers vector population from the measured values of $q 1$ and $q 2$. The detailed description of the procedure is given in reference [100]. In the following sections, the results obtained on the dislocation structures in bulk hexagonal nanomaterials by X-ray line profile analysis are summarized.

For obtaining fine-grained microstructure with high dislocation density SPD procedures were applied also on hexagonal metals, e.g. on commercially pure $\mathrm{Ti}[73,82$, 88, 94-97] and AZ91 Mg alloy [98]. Generally, the SPD processes on hexagonal materials are carried out at elevated temperatures because the rigidity of the specimens at room temperature. In commercilally pure $\mathrm{Ti}$ specimen processed by 8 ECAP passes at $673-723 \mathrm{~K}$, the dislocation density obtained from X-ray line profile analysis is $44 \cdot 10^{14} \mathrm{~m}^{-2}$. The relative fractions of the $\langle a\rangle,\langle c\rangle$ and $\langle c+a\rangle$ Burgers vectors are $62 \%, 0-4 \%$ and $32-36 \%$, respectively. The abundance of $\langle a\rangle$-type dislocations besides the $\langle c\rangle$ - and $\langle c+a\rangle$-type dislocations has been also found for other bulk hexagonal nanomaterials, e.g sintered WC [99] and SPD processed Mg alloys [98]. The relatively high fraction of $\langle c+a\rangle$ dislocations in $\mathrm{Ti}$ processed by ECAP can be attributed to the high temperature of deformation. Theoretical calculations and TEM observations for hexagonal metallic materials suggest the activation of $\langle c+a\rangle$ dislocations by strong deformation at elevated temperatures [100]. At room temperature the critical resolved shear stress of pyramidal $\langle c+a\rangle$ dislocations is about five times larger than that for basal slip [101], but this value decreases with increasing temperature. The dominance of the $\langle a\rangle$-type dislocations has been also found for $\mathrm{Ti}$ deformed by rolling at $268{ }^{\circ} \mathrm{C}$ [102]. The Burgers vector population has been evaluated as a function of reduction during hot rolling. It was found that the percentage of $\langle c+a\rangle$ dislocations is present significantly at $40 \%$ reduction rate, but decreases as the deformation proceeds to higher values. The presence of $\langle c\rangle$ dislocation type is minimal during the whole deformation process. The XLPA results are in good correlation with the texture evolution studies carried out on these samples.

The slip systems in ball-milled h.c.p. Ti sample is also studied by XLPA [103]. It was observed that ball milling leads to the formation of nanocrystalline grains and transform partially to an f.c.c. Ti-phase after $10 \mathrm{~h}$ of milling. Using a Rietveld analysis, the volume fraction of the f.c.c. phase was found to be about $24 \%$ with a crystallite size of $2 \mathrm{~nm}$. The origin of high strains is probably the dislocations present in the sample with the density of $10^{15} \mathrm{~m}^{-2}$. Anisotropic line broadening of the fault-unaffected reflections is explained in terms of anisotropic dislocation contrast corresponding to $\langle a\rangle$ and $\langle c+a\rangle$ dislocations. Both edge and screw dislocations were predicted with a significant basal slip.

The thermal stability of the ultrafine-grained microstructure in Ti was investigated by DSC [73]. As the temperature increases the relative fraction of the $\langle c+a\rangle$-type dislocations decreases down to between 0 and $4 \%$, indicating that these dislocations disappear faster than the $\langle a\rangle$ or $\langle c\rangle$-type ones (see Fig. 12). This can be explained by the fact that the $\langle c+a\rangle$-type dislocations have larger Burgers vectors and consequently higher formation energies than other two types.

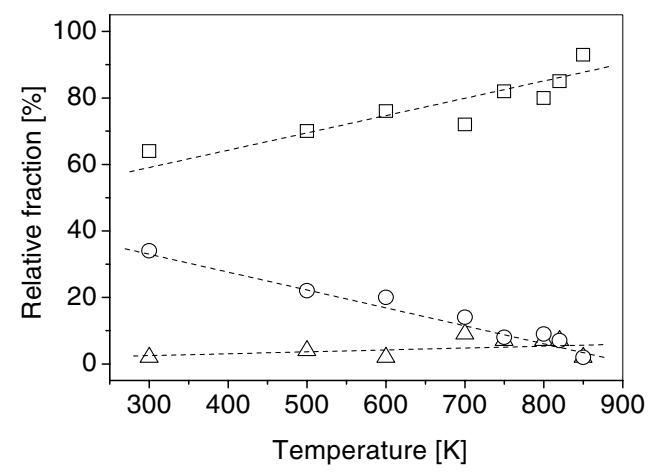

Fig. 12. Burgers vector populations as a function of annealing temperature for Ti processed by ECAP [73]. 
The ECAP process of AZ91 magnesium alloy was also carried out at high temperature $\left(270{ }^{\circ} \mathrm{C}\right)$ [98]. The main alloying elements in the AZ91 alloy are $9 \mathrm{wt} \% \mathrm{Al}, 1 \mathrm{wt} \%$ $\mathrm{Zn}$ and $0.2 \mathrm{wt} \% \mathrm{Mn}$. The dislocation density increases from $0.4 \cdot 10^{14} \mathrm{~m}^{-2}$ to $2 \cdot 10^{14} \mathrm{~m}^{-2}$ and the mean crystallite size decreases from $563 \mathrm{~nm}$ to $97 \mathrm{~nm}$ as a result of 8 ECAP passes. It was found that before ECAP the relative fractions of the $\langle a\rangle,\langle c\rangle$ and $\langle c+a\rangle$ Burgers vectors are $68-86 \%, 0-15 \%$ and $0-14 \%$, respectively. The abundance of $\langle a\rangle$-type dislocations can be explained similarly as for Ti. After high temperature ECAP the relative fractions of the $\langle a\rangle,\langle c\rangle$ and $\langle c+a\rangle$ Burgers vectors are changed to $54-58 \%, 0-2 \%$ and $38-42 \%$, respectively. The increase of the relative fraction of $\langle c+a\rangle$ dislocations is resulted by the strong deformation at high temperature. This phenomena was also observed for pure $\mathrm{Mg}$ deformed at high temperature [100]. The specimen processed by 8 ECAP passes was further deformed by tension at different temperatures [98]. At relatively low temperature the dominance of $\langle a\rangle$ type dislocations can be established. At high temperature, i.e. at $573 \mathrm{~K}$, the relative fraction of the $\langle a\rangle$ Burgers vector types decreases and the relative fraction of $\langle c+a\rangle$ dislocations increases. This is in agreement with the general observation that $\langle c+a\rangle$ dislocations are activated during strong plastic deformation at elevated temperatures.

\section{Ceramics}

The usual route of the production of dense nanocrystalline ceramic materials is the compaction of nanodisperse ceramic powders. The shape, the mean size and the size distribution of the crystallites of the starting ceramic powders are important factors in the kinetics of the sintering process and determine the density and the microstructure of the sintered ceramics. As a consequence, the study of the microstructural parameters for ceramic powders is essential.

The shape, size and size distribution of crystallites in nanocrystalline $\mathrm{ZnO}$ powder have been determined in [23, 104]. The classical Williamson-Hall plot of the FWHM shows a strong anisotropy [104]. The FWHM values in terms of $2 w_{f} \cos \theta$ are varying between $2 \cdot 10^{-3}$ and $11 \cdot 10^{-3}$ radians, where $w_{f}$ and $\theta$ are the half widths and the Bragg-angles of the physical profiles, respectively. The FWHM values of the harmonic pairs of reflections, especially of the 100-300, 002-004 and 101-202 are exactly identical within experimental errors indicating that the anisotropy in the FWHM values is solely due to size effects representing a special example of anisotropic peak broadening where strain is totally absent. The Fourier analysis of the data have also confirmed this behaviour. In the quantitative evaluation of the data the crystallites are modelled by cylinders. It was found that the axis of the cylinder was parallel to the hexagonal $c$ axis and the average diameter and height were 11 and $24 \mathrm{~nm}$, respectively. TEM micrographs have confirmed the same shape anisotropy and average size values, although they showed that the real shape of the crystallites is prism with irregular hexagonal cross section. The good correlation between the mean crystallite size determined by X-ray diffraction $(2.4 \mathrm{~nm})$ and that obtained from TEM micrographs $(3.5 \mathrm{~nm})$ was also observed for $\mathrm{CeO}_{2}$ ceramic powder [25, 105]. It was found that the strain contribution to peak broadening is also negligible for this material.

The crystallite size distribution of tungsten-carbide nanopowders obtained by ball-milling and the bulk specimen produced by sintering were studied by XLPA [27].

Figure 13 shows the X-ray line profiles of the $11 \overline{2} 1$ reflection corresponding to the ball-milled and compacted (open circles) and sintered (open squares) states of a tungsten-carbide specimen, respectively [27]. The long tail on the profile corresponding to the ball milled specimen indicates a wide size distribution, also proved by the more quantitative evaluation. The good agreement between the crystallite size distribution determined by line profile analysis and TEM is demonstrated in Fig. 14 for the sintered tungsten-carbide sample [27]. The bulk ultrafine-grained WC specimen was produced by ball-milling of submicron size powder and subsequent sintering at high temperature $(1693 \mathrm{~K})$. The high resolution SEM micrograph for this specimen is shown in Fig. 15.

Ceramic nanopowders can be produced from coarsegrained powders by mechanical milling or attrition, similarly as in the case of metallic materials. Mechanical attrition resulted in nanostructured microstructure of TiC powder with milling time as short as $15 \mathrm{~min}$ [106]. According

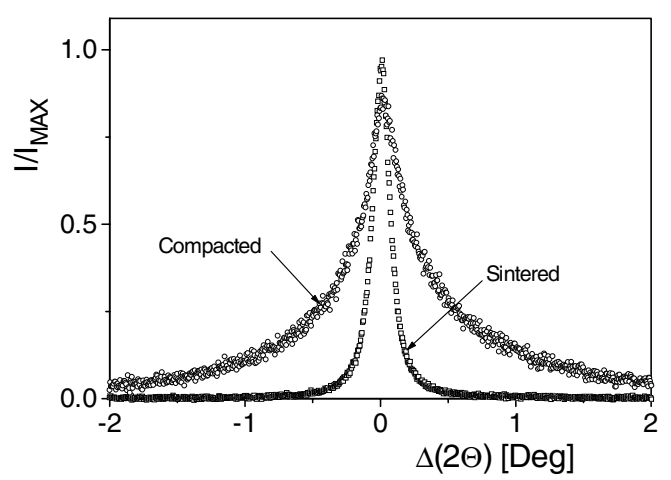

Fig. 13. X-ray line profiles of the $11 \overline{2} 1$ reflection corresponding to the ball-milled and compacted (open circles) and sintered (open squares) states of a tungsten-carbide specimen, respectively (by courtesy from [27]). The intensities are normalised by the peak maxima.

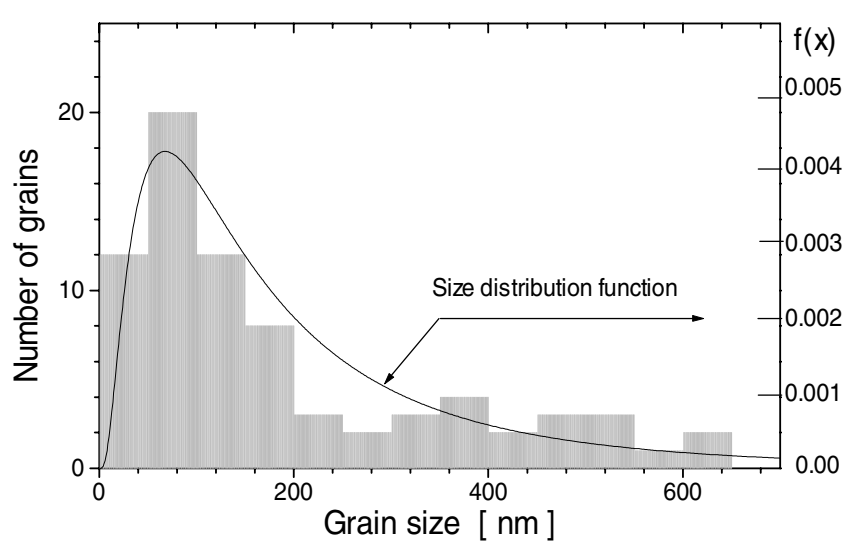

Fig. 14. Bar-diagram of the size distribution obtained from TEM and SEM micrographs and size-distribution functions, $f(x)$ (solid line), obtained by X-ray line profile analysis for a ball-milled and sintered tungsten-carbide specimen (by courtesy from [27]). 


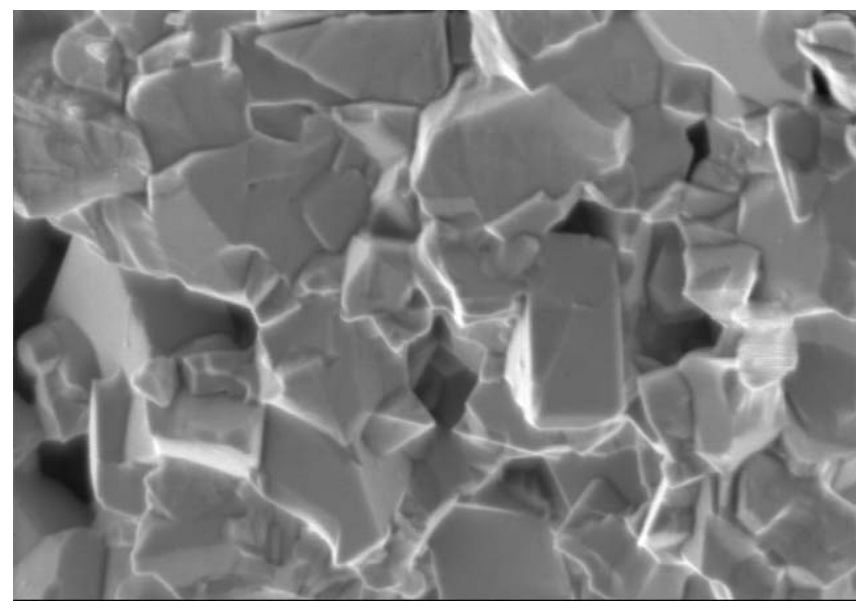

Fig. 15. High resolution scanning electron micrograph of the sintered tungsten-carbide specimen (by courtesy from [27]). The horizontal edge of the micrograph corresponds to $2 \mu \mathrm{m}$.

to XLPA, crystallite size decreased strongly during the first 3 hours of milling and it reached saturation value after $6 \mathrm{~h}$ milling time. An ultrafine-grained ceria stabilized tetragonal zirconia ceramic powder has been produced by $12 \mathrm{~h}$ ball milling of $\mathrm{ZrO}_{2}-5.5 \mathrm{~mol} \% \mathrm{CeO}_{2}-2 \mathrm{~mol} \% \mathrm{YO}_{1.5}$ powders in alcohol [107]. In these ceramics the $\mathrm{CeO}_{2}$ stabilizes the tetragonal structure of $\mathrm{ZrO}_{2}$. Increasing the temperature or under mechanical stress, the metastable tetragonal phase transforms to monoclinic structure. This martensitic tetragonal to monoclinic transformation in zirconia ceramics involves a 5\% volume expansion, which plays an important role in the improve of the fracture toughness. During ball milling a part of the volume of the tetragonal particles is transformed to monoclinic structure. As a consequence of this, the crystallite size of the tetragonal phase decreased, while the size of the monoclinic crystallites increased. The crystallite size obtained by line profile analysis was about $4-6 \mathrm{~nm}$ for both phases. At the same time the particle size determined from the specific surface area determined by Brunauer-Emmett-Teller (BET) method was about $10 \mathrm{~nm}$. We note that the difference in the crystallite and the particle sizes is caused by the coexistence of two phases in one particle. It was found that the stresses induced by milling in the tetragonal phase were released by the tetragonal to monoclinic transformation, while in the stresses in the monoclinic phase were accumulated. The ball milled powders were compacted and sintered at temperatures up to $1773 \mathrm{~K}$. The crystallite size of both phases increased monotonously with the sintering temperature from about 4-6 nm to 50-200 nm, however at $1573 \mathrm{~K}$ when an extensive tetragonal to monoclinic transformation occured the crystallite size of the tetragonal phase decreased.

The mean and the distribution of crystallite size in silicon nitride ceramic powders were determined by X-ray line profile analysis, TEM and specific surface area measurements separately and the values were compared to each other [108]. One series of $\mathrm{Si}_{3} \mathrm{~N}_{4}$ powders were prepared by gas-phase synthesis of silicon-tetrachloride and ammonia in thermal plasma reactor [109]. The majority (80 vol\%) of the as-synthesized powder was amorphous. Cystallization heat-treatment was carried out at 1523,
1623,1723 and $1773 \mathrm{~K}$ for $2 \mathrm{~h}$. With the increase of the temperature of the heat-treatments the crystalline volume fraction of the powder increased up to $80 \%$. Assuming that the crystallites have spherical form and log-normal size distribution, the area-weighted mean crystallite size was calculated from the median and the variance of the size distribution obtained from line profiles and was compared with that calculated by BET method. It was found that the mean size obtained from line profile analysis $(93 \mathrm{~nm})$ was in good agreement with that determined by BET method $(94 \mathrm{~nm})$ for the sample nearly fully crystallized at $1773 \mathrm{~K}$, demonstrating that the particles in this powder are single crystals. However, at lower temperatures the crystallite size obtained from line profile analysis was significantly higher than that calculated from BET method which can be explained by the smaller amorphous particles. From the two grain size values determined for the whole powder and the crystalline fraction, the size of the amorphous particles was obtained to be between 30 and $50 \mathrm{~nm}$ depending on the annealing temperature. The amorphous particle size also increased with the increase of the temperature of heat-treatment. The crystallite size distribution determined by X-ray line profile analysis was compared with the particle size distribution obtained from TEM micrographs. The particle size was determined from about 200 grains by the linear intercept method. It was found that the TEM particle size distribution contained somewhat smaller particles than those in the crystallite size distribution obtained from line profile analysis. This is unusual among the comparative studies of X-ray and TEM sizes since in general the grain size determined by $\mathrm{X}$-ray is smaller than that established by TEM. The phenomena can be explained by the smaller amorphous grains in the powder. Another silicon nitride powder produced by nitridation of silicon and subsequent milling was also investigated by X-ray line profile analysis [108, 109]. The area weighted mean crystallite size $(62 \mathrm{~nm})$ agreed well with the area weighted mean particle size determined by BET method $(71 \mathrm{~nm})$. The crystallite size distribution was also in very good agreement with that obtained from TEM micrographs.

In summary it can be concluded that for nanocrystalline ceramic powders the crystallite size distribution obtained from X-ray diffraction line profile analysis and the grain size distribution determined from TEM micrographs agree well. This means that the grains (or particles) in the ceramic powders are single crystals, i.e. in contrast with metals they are not divided into smaller domains, e.g. by dislocation cell-walls. In multiple-phase ceramic materials where the particles consists of crystallites of different phases, the particle size can be larger than the crystallite as shown in the case of zirconia ceramics [107]. In ceramic powders containing amorphous fraction the crystallite size can be smaller or higher than the particle size.

\section{Carbon and diamond}

Nanostructured carbon-based materials, e.g. diamond, SiC or carbon black, are important structural materials and also often used as filling components in composite matters. In 
spite of this fact only little attention has been paid to the line profile analysis investigation of the nanostructures developed in these materials.

Nanostructured bulk diamond specimens were prepared from micron-sized $(30-40 \mu \mathrm{m})$ synthetic diamond powder by high-pressure high-temperature (HPHT) compaction at a pressure of $2.0 \mathrm{GPa}$ and at selected temperatures in the $1070 \mathrm{~K}-1760 \mathrm{~K}$ range [110]. Raw diamond crystals had a low dislocation density of $0.3 \cdot 10^{14} \mathrm{~m}^{-2}$ which at high pressure conditions increased rapidly with increasing temperature up to $12 \cdot 10^{14} \mathrm{~m}^{-2}$. The increase of the dislocation density during HPHT compression is associated with the decrease of the crystallite size down to about 50$100 \mathrm{~nm}$. The grain-refinement in HPHT-treated diamond resulted from the rearrangement of the dislocation structure into a lower energy configuration, similarly as in metals during room temperature SPD processes. The density of dislocations was always greater in samples that were compressed and heated in water free environments (did not graphitize) than in partially graphitized samples [110]. At the lowest temperatures used in the experiments the difference in the population of dislocations between the two sets of samples was very small, but quickly increased and reached maximum at $1470 \mathrm{~K}$ and then decreased with further increase in temperature, compare Fig. 16. It is safe to assume that the dislocation distribution within the crystals is not uniform, and largest concentrations of defects are expected in close proximity of contact points where two crystals press one into another. Mobility of dislocations increases with increased temperature due to thermal activation. Dislocations may move into the interior of the crystal, consequently they do not impede the formation of new dislocations at the contact points. As a result, the dislocation density increases with temperature. As indicated by the increase of the parameter $q$, screw dislocations with low energy are preferentially produced at HPHT conditions. At very high temperatures $(1760 \mathrm{~K})$ the dislocations are annihilated as indicated by the decrease of the dislocation density. The decrease of the dislocation density at $1760 \mathrm{~K}$ is associated with the increase of the crystallite size which shows the recovery of the microstructue. In wet atmosphere the diamond is graphitized on the surface of the voids between the neighboring particles. The forma-

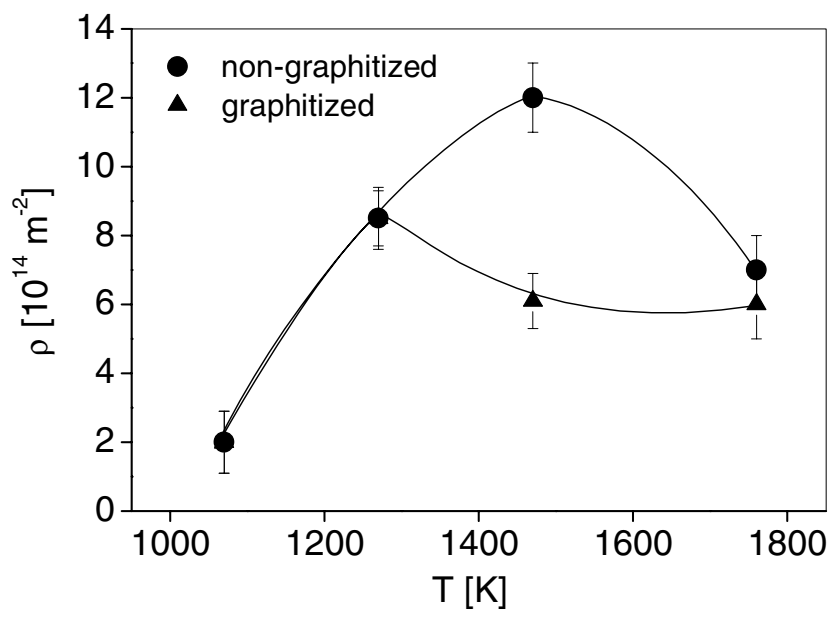

Fig. 16. Dislocation density in graphitized and not-graphitized diamond samples [110]. tion of graphite on the surface around the contact points lowers the shear stresses responsible for the dislocation production by increasing the contact surface between the diamond particles. Consequently, the dislocation density is lower and the grain-refinement is less effective in the graphitized samples.

The HPHT compression of nanopowders also results in bulk nanostructured diamond samples where the dislocation density increases with increasing the applied pressure of compression [111]. However, it was observed for $5 \mathrm{~nm}$ grain size diamond powders that the broadening of peak profiles is resulted rather by the small crystallite size and the stacking faults and not by dislocations, see Fig. 17 [112]. Assuming a shell-core model of the diamond nanoparticles, the defect structure of the internal region and the shell strains were obtained from the line broadening and the diffraction vector dependence of the apparent lattice parameter, respectively [112-114].

Bulk diamond - silicon carbide nanocomposite can be produced by silicon infiltration technique. During this process diamond and silicon powders are mixed and compressed at high pressure $(8 \mathrm{GPa})$ and high temperature $(2073-2273 \mathrm{~K})$. When temperature is increased, silicon melts and is pushed upward by external pressure and capillary effect to fill the gaps between diamond crystals. This process is accompanied by a reaction between carbon atoms from the diamond phase and liquid silicon to produce silicon carbide. It was found that as a result of high pressure, nanostructured diamond - silicon carbide composite formed by this technique either microcrystalline or nanocrystalline starting powders are used [115, 116]. The crystallite size of the diamond and $\mathrm{SiC}$ phases is smaller and the dislocation density is higher if nanocrystalline initial powders $(30-50 \mathrm{~nm})$ are used instead of microcrystalline counterparts $(1-60 \mu \mathrm{m})$. In spite of these results, the hardness of the specimens obtained from microcrystalline powders is much higher than those produced from nanopowders. The lower porosity of the specimens compacted from nanosized powders can be attributed to the higher porosity. The increased porosity is connected to the socalled "bottle neck" effect. Although the two precursors,

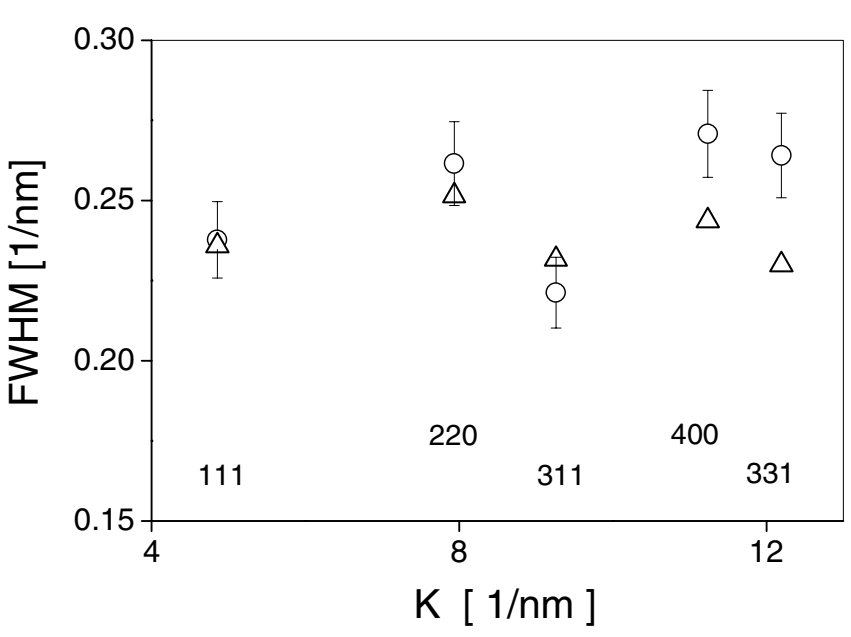

Fig. 17. The full width at half maximum (FWHM) of the line profiles as a function of the length of the diffraction vector $(\mathrm{K})$ for nanodiamond specimen (open circles). The calculated FWHM values for $5 \mathrm{~nm}$ diamond containing stacking faults are plotted as open triangles [112]. 
diamond and silicon nanosize powders, were thoroughly mixed, a reaction between nanosize diamond and silicon results in $\mathrm{SiC}$ which may restrict motion of liquid silicon and thus result in cavities. Increased temperature leads to a reduction of silicon viscosity allowing for a more efficient penetration of the specimen and thus more uniform distribution of $\mathrm{SiC}$. When larger diamond crystals are used, then the average diameter of the channels through which liquid silicon can flow are sufficiently large and cannot be easily closed by the $\mathrm{SiC}$ phase formed as a result of reactive sintering.

Carbon black is generally used as a filler in rubber production to modify the mechanical properties of the tire. Although the smallest indivisible unit of carbon black is the aggregate, in the TEM images aggregates appear to be formed by spherical particles, which are fused together. Aggregates connect through van der Waals forces into networks called agglomerates. Internal structure of aggregates is not well understood. Graphite-like nanosize domains have been detected in carbon black particles, in which the basal planes are parallel but angularly distorted and the spacing between the layers is different from that of pure graphite. The microstructure of carbon black particles are important factors in determining the reinforcing properties of carbon black in rubber. The amorphous fraction of carbon at the surface of the particles, the mean crystallite size, the size distribution and the strain affect the strength of bonding between the carbon black and the rubber in tires. Warren and Bodenstein [117] computed diffraction patterns of carbon blacks assuming turbostratically arranged layer structures in which blocks of parallel layers normal to the $c$ direction have small but finite size: $L_{c}$. The numerically calculated diffraction pattern for $L_{c}=1.38 \mathrm{~nm}$ and the lateral size of the blocks $L_{a}=2.0 \mathrm{~nm}$ [117]. It is important to note that in this model calculation of strain was not included.

The effect of graphitization and pressure treatment on the microstructure and internal stresses of carbon blacks is studied by XLPA [118, 119]. The Fourier transforms of the experimental line profiles are fitted by theoretical functions based on the model of the microstructure. In this model the crystallites are ellipsoids with log-normal size distribution. The results obtained by line profile analysis are plotted in Fig. 18. It was found that in raw carbon

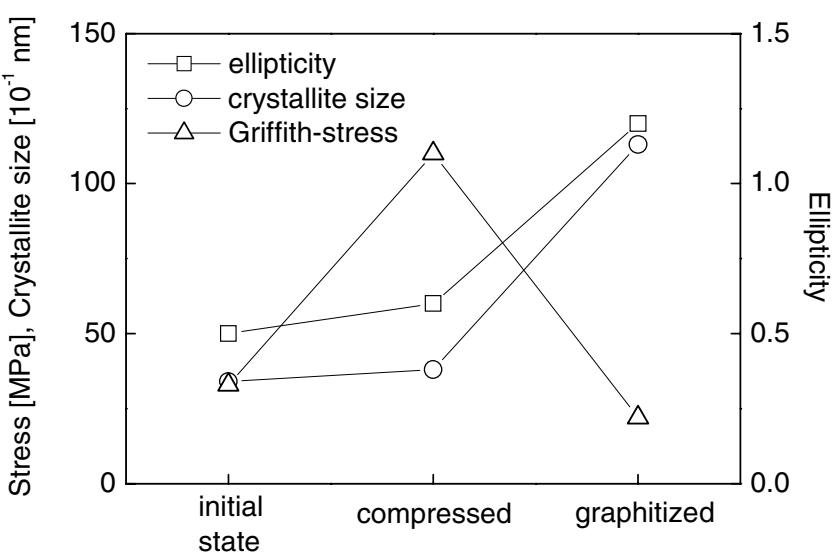

Fig. 18. The ellipticity, the crystallite size in the lateral direction and the Griffith-stress for initial, compressed and graphitized carbon black specimens [119]. blacks crystallites have lateral dimensions twice the size in the hexagonal $c$ direction. During graphitization process caused by heat treatment the lateral size of crystallites grow from about $3 \mathrm{~nm}$ to $11 \mathrm{~nm}$ and their shapes becomes more spherical. The pressure has no effect on the size and shape of crystallites. The microstresses have been evaluated in terms of crystal dislocations. Since, however, the presence of dislocations in carbon black has not yet been verified experimentally, the formal dislocation density has been converted to stresses prevailing between crystallites attached to each other by necking. The conversion has been carried out by using the Griffith model of stresses in strained cracks [119]. It is found that compression induces heterogeneous internal microstresses, whereas, heat treatment slightly decreases these stresses. It should be noted that the contact stresses developed between $\mathrm{SiC}$ particles due to external pressure has been also studied by Palosz and coworkers [120]. The asymetry of the line profiles was interpreted as a result of the different lattice parameters of the core and shell regions of the particles.

\section{The interpretation of coherently scattering domains as subgrains, especially in bulk materials}

According to the theorem of Bertaut [121] the profile of a size broadened peak can be obtained as the sum of the intensities diffracted by parallel and independent columns which build up the diffracting crystallites and aligned normal to the reflecting planes with unit cross sectional area. The diffraction peak corresponding to one particular column is the squared Fourier transform of the form function pertaining to that column length. The final size-broadened peak is the volume-weighted sum of the individual peaks corresponding to the individual columns. The direct meaning of a size broadened peak is thus related to the (area and/or volume) weighted column-length distribution in the specimen. The column-length distribution in the specimen depends on the size, the shape and the size distribution of the crystallites. In order to obtain the (area and/or volume weighted) mean size of crystallites or their distributions, specific assumptions have to be made about the shape and the size-distribution of these objects [24]. Size broadening of line profiles has been treated for spherical or non-spherical crystallites [23, 25, 37, 104, 122-126].

Crystallite size determined by XLPA is usually, either equal or smaller than determined by TEM [83]. In those cases when the crystallites or particles are delineated by well defined boundaries, as in the case of metallic samples produced by the method of inert gas condensation [57] or in the case of loose particles of ceramic materials [26, $109,122,127]$ the X-ray and TEM data are in good correlation. In the case of bulk ultra-fine grained materials formed by SPD methods, however, the X-ray size values are usually smaller than the TEM data, cf. [69, 80, 81, 128]. The arrangement of dislocations into small angle grain boundaries provide a simple and straightforward model for subgrain/cell structure where the TEM grain size is obviously larger than the X-ray subgrain/cell size, as shown schematically in [129] and [83]. The thorough 
and systematic measurements of differences in orientation between adjacent subgrains in an ECAP deformed copper specimen Hellmig et al. [130] have shown, however, that considerable fractions of subgrains are not separated by significant differences in orientation. These TEM investigations indicate that the small angle grain boundary model of subgrain boundaries is definitely not sufficient to explain the apparent discrepancy between TEM and X-ray size values. In [83] it was shown that when dislocations are arranged in dipolar dislocation-wall configurations the two crystal-halfs on either side of such a wall are shifted with respect to each other parallel to the direction of their Burgers vectors, where this shift varies randomly between zero and $\underline{b} / 2$. This random spatial shift causes a random phase shift of the X-rays scattered by the adjacent subgrains. As a result, the intensities of the scattering from adjacent subgrains will be summed up and the line broadening will be determined by the average subgrain size. The two models, i.e. the small-angle grain-boundary (SAGB) model and the dipolar dislocation-wall (DDW) model of subgrain boundaries, provide together a physically well established basis for the assumption that size and size-distributions determined by X-ray line profile analysis correspond to subgrains or dislocation cells. If, however, the subgrains/cells and the grains are identical, as it might happen in many cases, then the TEM and X-ray size data can be identical. Finally it is noted that, neither dipolar dislocation walls nor small angle grain boundaries are perfect arrays of dislocations. The arrays will not be perfectly regular and the dislocations maybe of different type and/or orientation and/or sign. For example there may be some dipoles within the small angle grain boundaries or, the dipolar walls may be not straight or flat and they may also contain different types of dislocations or more dislocations of one sign, thus causing some orientation differences on the two sides of the dipolar wall. This would mean that the two types of subboundaries can be mixed together, which supports even more the concept that the X-ray size is closest to the average size of subgrains, especially when it is smaller than TEM grain size.

\section{Conclusions}

$\mathrm{X}$-ray line profile analysis based on X-ray powder diffraction patterns is a powerful tool to investigate the microstructure of nanocrystalline materials in terms of crystallite size and size distribution, and microstrains, especially dislocation densities, dislocation character and active slip systems, and planar defects, in particular stacking faults and twin boundaries. When combined with other methods, especially electron microscopy, the interpretation of the microstructure parameters provided by the X-ray method is greatly facilitated. On the other hand, the X-ray method yields indispensable average values of the microstructure parameters, practically inaccessible by electron microscopy.

Acknowledgments. The authors are grateful for the financial support of the Hungarian National Science Foundation, OTKA T46990, F047057 and T43247. This work was supported by the Bolyai Janos Research Scholarship of the Hungarian Academy of Sciences.

\section{References}

[1] Gleiter, H.: Nanostructured materials. Adv. Mater. 4 (1992) 474-481.

[2] Weertman, J. R.; Sanders, P. G.: Plastic Deformation of Nanocrystalline Metals. Solid State Phenomena. 35-36 (1994) 249262.

[3] Janot, R.; Guérard, D.: Ball-milling in liquid media: Applications to the preparation of anodic materials for lithium-ion batteries. Progr. Mater. Sci. 50 (2005) 1-92.

[4] Munir, Z. A.; Holt, J. B. (Editors): Combustion and Plasma Synthesis of High-Temparature Materials. Wiley-VCH Verlag. 1990.

[5] Guillou, N.; Auffrédic, J. P.; Louër, D.: The early stage of crystallite growth of obtained from a cerium oxide nitrate. Powder Diffr. 10 (1995) 236.

[6] Ravishankar, R.; Kirschhock, C. E. A.; Knops-Gerrits, P. P.; Feijen, E. J. P.; Grobet, P. J.; Vanoppen, P.; De Schryver, F. C.; Mieche, G.; Fuess, H.; Schoeman, B. J.; Jacobs, P. A.; Martens, J. A.: Characterization of nanosized material extracted from clear suspensions for MFI zeolite synthesis. J. Phys. Chem. B103 (1999) 4960-4964.

[7] Segal, V. M.: Materials processing by simple shear. Mater. Sci. Eng. A197 (1995) 157-164.

[8] Valiev, R. Z.; Islamgaliev, R. K.; Alexandrov, I. V.: Bulk nanostructured materials from severe plastic deformation. Progr. Mater. Sci. 45 (2000) 103-189.

[9] Schafler, E.; Pippan, R.: Effect of thermal treatment on microstructure in high pressure torsion (HPT) deformed nickel. Mater. Sci. Eng A387-389 (2004) 799-804.

[10] Macherauch, E.; Hauk, V.: Residual Stresses. DGM Inform. Verlag, 1986.

[11] Noyan, I. C.; Cohen, J. B.: Residual stress: measurement by diffraction and interpretation. Spinger-Verlag. New York, 1987.

[12] Warren, B. E.: X-ray Studies of Deformed Metals. Progr. Metal Phys. 8 (1959) 147-202.

[13] Wilson, A. J. C.: X-Ray Optics, the Diffraction of X-Rays by Finite and Imperfect Crystals. London, Methuen, 1962.

[14] Treacy, M. M. J.; Newsam, J. M.; Deem, M. W.: A general recursion method for calculating diffracted intensities from crystals containing planar faults. Proc. Roy. Soc. London A433 (1991) 499-520.

[15] Ustinov, A. I.: Defect and Microstructure Analysis by Diffraction (Eds. R. L. Snyder, J. Fiala, and H. J. Bunge) pp. 264-317. Oxford University Press, 1999.

[16] Scardi, P.; Leoni, M.: Fourier modelling of the anisotropic line broadening of X-ray diffraction profiles due to line and plane lattice defects. J. Appl. Cryst. 32 (1999) 671-682.

[17] Estevez-Rams, E.; Penton-Madrigal, A.; Lora-Serrano, R.; Martinez-Garcia, J.: Direct determination of microstructural parameters from the X-ray diffraction profile of a crystal with stacking faults. J. Appl. Cryst. 34 (2001) 730-736.

[18] Estevez-Rams, E.; Leoni, M.; Scardi, P.; Aragon-Fernandez, B.; Fuess, H.: On the powder diffraction pattern of crystals with stacking faults. Philosophical Magazine. 83 (2003) 4045-4057.

[19] Kuznetsov, A.; Dmitriev, V.; Langenhorst, F.; Estevez-Rams, E.; Dubrovinskay, L.: Stacking Faults and Internal Strains in DHCP Phase of La. Acta Cryst. A61 (2005) C451.

[20] Dittrich, H.; Wohlfahrt-Mehrens, M.: Stacking fault analysis in layered materials. International Journal of Inorganic Materials 3 (2001) 1137-1142.

[21] Balogh, L.; Ribárik G.; Ungár, T.: Stacking Faults and Twin Boundaries in fcc Crystals Determined by X-ray Diffraction Profile Analysis. J. Appl. Phys. 100 (2006) 023512.

[22] Langford J. I.; Louër, D.: High-resolution powder diffraction studies of copper(II) oxide. J. Appl. Cryst. 24 (1991) 149-155.

[23] Langford, J. I.; Boultif, A.; Auffredic, J. P.; Louër, D.: Use of pattern decomposition to study the combined X-ray diffraction effects of crystallite size and stacking faults in ex-oxalate zinc oxide. J. Appl. Cryst. 26 (1993) 22-33.

[24] Langford, J. I.; Louër, D.: Powder diffraction. Rep. Prog. Phys. 59 (1996) 131-234.

[25] Langford, J. I.; Louër D.; Scardi, P.: Effect of a crystallite size distribution on X-ray diffraction line profiles and whole-powderpattern fitting. J. Appl. Cryst. 33 (2000) 964-974. 
[26] Scardi, P.; Leoni, M.: Whole powder pattern modelling. Acta Cryst. A58 (2002) 190-200.

[27] Ungár, T.; Borbély, A.; Goren-Muginstein, G. R.; Berger S.; Rosen, A. R.: Particle-size, size distribution and dislocations in nanocrystalline tungsten-carbide. Nanostructured Materials 11 (1999) 103-113.

[28] Ungár, T.; Leoni M.; Scardi, P.: The dislocation model of strain anisotropy in whole powder-pattern fitting: The case of an Li-Mn cubic spinel. J. Appl. Cryst. 32 (1999) 290-295.

[29] Krivoglaz, M. A.: X-ray and Neutron Diffraction in Nonideal Crystals, Springer-Verlag. Berlin. Heidelberg. New York, 1996.

[30] Krivoglaz, M. A.; Ryaboshapka, K. P.: The effect of dislocations on line profiles. Fiz. Met. Metallovod. 15 (1963) 18-27.

[31] Wilkens, M.: Determination of density and distribution of dislocations in deformed single crystals from broadened X-ray diffraction profiles. phys. stat. sol. (a) 2 (1970) 359-370.

[32] Wilkens, M.: Fundamental Aspects of Dislocation Theory (Eds. J. A. Simmons, R. de Wit, R. Bullough) p. 1195. Nat. Bur. Stand. Spec. Publ. Vol. II. No. 317. Washington DC. USA. 1970.

[33] Wilkens, M.: Proc. 8th Int. Conf. Strength Met. Alloys (ICSMA 8). Tampere. Finland. (Eds. P. O. Kettunen, T. K. Lepistö, M. E. Lehtonen) p. 47. Pergamon Press. 1988.

[34] Groma, I.; Ungár T.; Wilkens, M. J.: Asymmetric X-ray-line broadening of plastically deformed crystals. 1. Theory. Appl. Cryst. 21 (1988) 47-53.

[35] Ungár, T.; Groma I.; Wilkens, M.: Asymmetric X-ray-line broadening of plastically deformed crystals.2. Evaluation procedure and application to [001]-Cu crystals. J. Appl. Cryst. 22 (1989) 26-34.

[36] Groma, I.: X-ray line broadening due to an inhomogeneous dislocation distribution. Phys. Rev. B57 (1998) 7535-7542.

[37] Ungár, T.; Gubicza, J.; Ribárik, G.; Borbély, A.: Crystallite size distribution and dislocation structure determined by diffraction profile analysis: Principles and practical application to cubic and hexagonal crystals. J. Appl. Cryst. 34 (2001) 298-310.

[38] Ribárik, G.; Ungár, T.; Gubicza, J.: MWP-fit: A program for multiple whole-profile fitting of diffraction peak profiles by ab initio theoretical functions. J. Appl. Cryst. 34 (2001) 669-676.

[39] Ungár, T.; Mughrabi, H.; Rönnpagel D.; Wilkens, M.: X-ray line-broadening study of the dislocation cell structure in deformed [001]-orientated coper single crystals. Acta Met. 32 (1984) 333-342.

[40] Mughrabi, H.; Ungár, T.; Kienle W.; Wilkens, M.: Long range internal stresses and asymmetric X-ray line broadening in tensile-deformed [001]-orientated coper single crystals. Phil. Mag. A53 (1986) 793-813.

[41] Lahrman, D.; Field, R.; Darolia R.; Fraser, H.: Investigation of techniques for measuring lattice mismatch in a rhenium containing nickel base superalloy. Acta metall. 36 (1988) 1309-1320.

[42] Kuhn, H. A.; Biermann, H.; Ungár, T.; Mughrabi, H.: X-ray study of creep-deformation induced changes of the lattice mismatch in the $\gamma^{\prime}$-hardened monocrystalline nickel-base superalloy SRR 99. Acta Met. Mater. 39 (1991) 2783-2794.

[43] Caglioti, G.; Paoleti, A.; Ricci, F. P.: Choice of Collimators for a Crystal Spectrometer for Neutron Diffraction. Nucl. Instrum. 3 (1958) 223-228.

[44] Wu, E.; MacA. Gray, E.; Kisi, E. H.: Modelling DislocationInduced Anisotropic Line Broadening in Rietveld Refinements Using a Voigt Function. II. Application to Neutron Powder Diffraction Data. J. Appl. Cryst. 31 (1998) 356-368.

[45] Cheary, R. W.; Dooryhee, E.; Lynch, P.; Armstrong, N.; Dligatch, S.: X-ray diffraction line broadening from thermally deposited gold films. J. Appl. Cryst. 33 (2000) 1271-1283.

[46] Dinnebier, R. E.; Von Dreele, R.; Stephens, P. W.; Jelonek S.; Sieler, J.: Structure of sodium para-hydroxybenzoate, $\mathrm{NaO}_{2} \mathrm{C}-\mathrm{C}_{6} \mathrm{H}_{4} \mathrm{OH}$ by powder diffraction: Application of a phenomenological model of anisotropic peak width. J. Appl. Cryst. 32 (1999) 761-769.

[47] Kuzel Jr., R.; Klimanek, P.: X-ray diffraction line broadening due to dislocations in non-cubic materials. 2. The case of elastic-anisotropy applied to hexagonal crystals. J. Appl. Cryst. 21 (1988) 363-368.

[48] Kuzel Jr., R.; Klimanek, P.: X-ray diffraction line broadening due to dislocations in non-cubic materials. 3. Experimental results for plastically deformed zirconium. J. Appl. Cryst. 22 (1989) 299-307.

[49] Popa, N. C.: The ( $h k l)$ Dependence of Diffraction-Line Broadening Caused by Strain and Size for all Laue Groups in Rietveld Refinement. J. Appl. Cryst., 31 (1998) 176-180.

[50] Ungár, T.; Gubicza, J.; Hanák, P.; Alexandrov, I.: Densities and character of dislocations and size-distribution of subgrains in deformed metals by X-rays diffraction profile analysis. Mater. Sci. Eng. A319-321 (2001) 274-278.

[51] Stephens, P. W.: Phenomenological Model of Anisotropic Peak Broadening in Powder Diffraction. J. Appl. Cryst. 32 (1999) 281-289.

[52] Ungár, T.; Borbély, A.: The effect of dislocation contrast on X-ray line broadening: a new approach to line profile analysis. Appl. Phys. Lett. 69 (1996) 3173-3175.

[53] Ungár, T.; Ott, S.; Sanders, P.; Borbély, A.; Weertman, J. R.: Dislocations, grain size and planar faults in nanostructured copper determined by high resolution X-ray diffraction and a new procedure of peak profile analysis. Acta mater. 46 (1998) 36933699.

[54] Ungár, T.; Révész, Á.; Borbély, A.: Dislocations and grain size in electrodeposited nanocrystalline $\mathrm{Ni}$ determined by the modified Williamson-Hall and Warren-Averbach procedures. J. Appl. Cryst. 31 (1998) 554-558

[55] Ungár, T.; Tichy, G.: The effect of dislocation contrast on X-ray line profiles in untextured polycrystals. Phys. Stat. Sol. A147 (1999) 425-434.

[56] Ungár, T.; Martinetto, P.; Ribárik, G.; Dooryhée, E.; Walter, Ph.; Anne, M.: Revealing the powdwring methods of black makeup in Ancient Egypt by fitting microstructure based Fourier coefficients to whole X-ray diffraction profiles of galena. Journal of Appiled Physics. 91 (2002) 2455-2465.

[57] Krill, C. E.; Birringer, R.: Estimating Grain-Size Distributions in Nanocrystalline Materials form X-Ray Diffraction Profile Analysis. Phil. Mag. 77 (1998) 621-640.

[58] Sanders, P. G.; Fougere, G. E.; Thompson, L. J.; Eastman, J. A.; Weertman, J. R.: Improvements in the synthesis and compaction of nanocrystalline materials. Nanostruct. Mater. 8 (1997) 243 252.

[59] Mitra, T.; Ungár, T.; Morita, P. G.; Sanders, P; Weertman, J. R.: Assessment of Grain Size Distributions in Nanocrystalline Copper and Their Effect on Mechanical Behavior. Advanced Materials for the 21st Century. (Eds. Y. W. Chung, D. C. Durand, P. K. Liaw, G. B. Olson) pp. 553-564. TMS. Warrendale. 1999.

[60] Tian, H. H.; Atzmon, M.: Kinetics of microstructure evolution in nanocrystalline $\mathrm{Fe}$ powder during mechanical attrition. Acta mater. 47 (1999) 1255-1261.

[61] Révész, Á.; Ungár, T.; Borbély A.; Lendvai, J.: Dislocations and grain size in ball-milled iron powder. Nanostr. Mater. 7 (1996) 779-788

[62] Gubicza, J.; Kassem, M.; Ribárik, G.; Ungár, T.: The microstructure of mechanically alloyed Al-Mg determined by X-ray diffraction peak profile analysis. Mat. Sci. Eng. A372 (2004) $115-122$.

[63] Natter, H.; Hempelmann, R.: Nanocrystalline copper by pulsed electrodeposition: The effects of organic additives, bath temperature, and pH. J. Phys. Chem. 100 (1996) 19525-19532.

[64] Natter, H.; Schmelzer, M.; Löffler, M.-S.; Krill, C. E.; Fitch, A.; Hempelmann, R.: Grain-growth kinetics of nanocrystalline iron studied in situ by synchrotron real-time X-ray diffraction. J. Phys. Chem. 104 (2000) 2467-2476.

[65] Natter, H.; Löffler, M. S.; Krill, C. E.; Hempelmann, R.: Crystallite growth of nanocrystalline transition metals studied in situ by high temperature synchrotron X-ray diffraction. Scripta Mater. 44 (2001) 2321-2325.

[66] Löffler, M.-S.; Natter, H.; Hempelmann, R.; Wippermann, K.: Electrochimica Acta, Preparation and characterisation of $\mathrm{Pt}-\mathrm{Ru}$ model electrodes for the direct methanol fuel cell. 48 (2003) 3047-3051.

[67] Thiele, E.; Klemm, R.; Hollang, L.; Holste, C.; Schell, N.; Natter, H.; Hempelmann, R.: An approach to cyclic plasticity and deformation-induced structure changes of electrodeposited nickel. Mat. Sci. Eng. A390 (2005) 42-51. 
[68] Natter, H.; Krajewski, T.; Hempelmann, R.: Nanocrystalline palladium by pulsed electrodeposition. Ber. Bunsenges. Phys. Chem. 100 (1996) 55-64.

[69] Gubicza, J.; Chinh, N. Q.; Horita, Z.; Langdon, T. G.: Effect of $\mathrm{Mg}$ addition on microstructure and mechanical properties of aluminum. Mater. Sci. Eng. A387-389 (2004) 55-59.

[70] Fátay, D.; Bastarash, E.; Nyilas, K.; Dobatkin, S.; Gubicza, J.; Ungár, T.: X-ray diffraction study on the microstructure of $\mathrm{Al}-5.9 \% \mathrm{Mg}-0.3 \% \mathrm{Sc}-0.18 \% \mathrm{Zr}$ alloy deformed by high pressure torsion. Z. Metallkunde. 94 (2003) 842-847.

[71] Gubicza, J.; Krállics, Gy.; Schiller, I.; Malgin, D.: Evolution of the Microstructure of Al 6082 Alloy during Equal-Channel Angular Pressing. Mater. Sci. Forum 473-474 (2004) 453-458.

[72] Dubravina, A; Zehetbauer, M. J.; Schafler, E; Alexandrov, I. V.: Correlation between domain size obtained by X-ray Bragg profile analysis and macroscopic flow stress in severely plastically deformed copper. Mater. Sci. Eng. A387 (2004) 817-821.

[73] Gubicza, J.; Nam, N. H.; Balogh, L.; Hellmig, R. J.; Stolyarov, V. V.; Estrin, Y.; Ungár, T.: Microstructure of severely deformed metals determined by X-ray peak profile analysis. J. Alloys and Compounds 378 (2004) 248-252.

[74] Dalla Torre, F.; Lapovok, R.; Sandlin, J.; Thomson, P. F.; Davies, C. H. J.; Pereloma, E. V.: Microstructures and properties of copper processed by equal channel angular extrusion for 1-16 passes. Acta Mater. 52 (2004) 4819-4832.

[75] Gubicza, J.; Balogh, L.; Hellmig, R. J.; Estrin, Y.; Ungár, T.: Dislocation structure and crystallite size in severely deformed copper by X-ray peak profile analysis. Mater. Sci. Eng. A400401 (2005) 334-338.

[76] Kuzel, R.; Matej, Z.; Cherkaska, V.; Pesicka, J.; Cízek, J.; Procházka, I.; Islamgaliev, R. K.: Structural investigations of submicrocrystalline metals obtained by high-pressure torsion deformation. J. Alloys and Comp. 378 (2004) 242-247.

[77] Kuzel, R.; Cernansky, M.; Holy, V.; Kubena, J.; Simek D.; Kub, J.: Diffraction analysis of the microstructure of materials. (Eds. E. J. Mittemeijer, P. Scardi) p. 229. Springer. Berlin, 2004.

[78] Schafler, E.; Dubravina, A.; Mingler, B.; Karnthaler, H. P.; Zehetbauer, M.: On the microstructure of HPT processed $\mathrm{Cu}$ under variation of deformation parameters. Mater. Sci. Forum 503-504 (2006) 51-56.

[79] Skrotzki, W.; Tamm, R.; Klemm, R.; Thiele, E.; Holste, C.; Baum, H.: Textural and microstructural characterization of equal channel angular pressed nickel. Mater. Sci. Forum. 408-4 (2002) 667-672.

[80] Zhilyaev, A. P.; Gubicza, J.; Nurislamova, G.; Révész, Á.; Suriñach, S.; Baró, M. D.; Ungár, T.: Microstructural Characterization of Ultrafine-Grained Nickel. Phys. Stat. Sol. (a) 198 (2003) 263-271.

[81] Zhilyaev, A. P.; Gubicza, J.; Suriñach, S.; Baró M. D.; Langdon, T. G.: Calorimetric and X-ray measurements in ultrafinegrained nickel. Mater. Sci. Forum 426 (2003) 4507-4512.

[82] Zhu, Y. T.; Huang, J. Y.; Gubicza, J.; Ungár, T.; Wang, Y. M.; Ma, E.; Valiev, R. Z.: Nanostructures in Ti Processed by Severe Plastic Deformation. J. Mat. Res. 18 (2003) 1908-1917.

[83] Ungár, T.; Tichy, G.; Gubicza J.; Hellmig, R. J.: Correlation between subgrains and coherently-scattering-domains. Powder Diffr. 20 (2005) 366-375.

[84] Kasai, M;. Matsubara, E.; Saida, J.; Nakayama, M.; Uematsu, K.; Zhang, T.; Inoue, A.: Crystallisation behaviour of $\mathrm{CU}_{60} \mathrm{Zr}_{30} \mathrm{Ti}_{10}$, bulk glassy alloy. Mater. Sci. Eng. A375-377 (2004) 744-748.

[85] Gubicza, J.; Ribárik, G.; Bakonyi, I.; Ungár, T.: Crystallite-size distribution and dislocation structure in nanocrystalline $\mathrm{HfNi}_{5}$ determined by X-ray diffraction profile analysis. J. Nanosci. and Nanotechn. 1 (2001) 343-348.

[86] Wang, J. Q.; Zhang, H. W.; Gu, X. J.; Lu, K.; Sommer, F.; Mittemeijer, E. J.: Kinetics of primary nanocrystallization in Al-rich metallic glass with quenched-in nuclei. Mater. Sci. Eng. A375-377 (2004) 980-984.

[87] Bose, P.; Bid, S.; Pradhan, S. K.; Pal, M.; Chakravorty, D.: $\mathrm{X}$-ray characterization of nanocrystalline $\mathrm{Ni}_{3} \mathrm{Fe}$. J. Alloys Compounds. 343 (2002) 192-198.

[88] Schafler, E.; Zeipper, L.; Zehetbauer, M. J.: Proc. $2^{\text {nd }}$ International Conference on Nanomaterials by Severe Plastic Deformation: Fundamentals - Processing - Applications. (Eds.
M. J. Zehetbauer, R. Z. Valiev). pp. 426-432. J. Wiley VCH. Weinheim. 2004.

[89] Wang, Y. M.; Chen, M. W.; Zhou, F. H.; Ma, E.: High tensile ductility in a nanostructured metal. Nature 419 (2002) 912-915.

[90] Borbely, A.; Dragomir-Cernatescu, I.; Ribarik, G.; Ungar, T.: Computer program ANIZC for the calculation of diffraction contrast factors of dislocations in elastically anisotropic cubic, hexagonal and trigonal crystals. J. Appl. Cryst. 36 (2003) 160-165.

[91] Ungár, T.; Dragomir, I.; Révész, A.; Borbély, A.: The contrast factors of dislocations in cubic crystals: the dislocation model of strain anisotropy in practice. J. Appl. Cryst. 32 (1999) 9921002.

[92] Dragomir, I. C.; Ungar, T.: Contrast factors of dislocations in the hexagonal crystal system. J. Appl. Cryst. 35 (2002) 556564.

[93] Klimanek, P.; Kuzel, Jr R.: X-ray diffraction line broadening due to dislocations in non-cubic materials.1. General considerations and the case of elastic isotropy applied to hexagonal crystals. J. Appl. Cryst. 21 (1988) 59-65.

[94] Gubicza, J.; Dragomir, I. C.; Ribárik, G.; Baik, S. C.; Zhu, Y. T.; Valiev R. Z.; Ungár, T.: Dislocation structure and crystallite size-distribution in plastically deformed Ti determined by X-ray peak profile analysis, Zeitschrift für Metallkunde. 94 (2003) $1185-1188$.

[95] Gubicza, J.; Dragomir, I. C.; Ribárik, G.; Zhu, Y. T.; Valiev, R. Z.; Ungár, T.: Microstructure of severely deformed titanium from X-ray diffraction profile analysis. Mater. Sci. Forum 414415 (2003) 229-234.

[96] Zeipper, L. F.; Zehetbauer, M. J.; Holzleithne, Ch.: Defect based micromechanical modelling and simulation of nano SPD $\mathrm{CP}-\mathrm{Ti}$ in post-deformation. Mater. Sci. Eng. A410-411 (2005) $217-221$.

[97] Mingler, B.; Stolyarov, V. V.; Zehetbauer, M.; Lacom, W.; Karnthaler, H. P.: TEM investigations of Titanium processed by ECAP followed by cold rolling. Mater. Sci. Forum 503-504 (2006) 805-810.

[98] Máthis, K.; Gubicza, J.; Nam, N. H.: Microstructure and mechanical behavior of AZ91 Mg-alloy processed by Equal Channel Angular Pressing. J. Alloys and Comp. 394 (2005) 194199.

[99] Gubicza, J.; Ribárik, G.; Goren-Muginstein, G. R.; Rosen, A. R.; Ungár, T.: The density and the character of dislocations in cubic and hexagonal polycrystals determined by X-ray diffraction. Mater. Sci. Eng. A309-310 (2001) 60-63.

[100] Mathis, K.; Nyilas, K.; Axt, A.; Dragomir-Cernatescu, I.; Ungar, T.; Lukac, P.: The evolution of non-basal dislocations as a function of deformation temperature in pure magnesium determined by X-ray diffraction. Acta Mater 52 (2004) 2889-2894.

[101] Yoo, M. H.: Slip, twinning and fracture in hexagonal closepacked metals. Metall. Trans. A12 (1981) 409-418.

[102] Dragomir, I. C.; Li, D. S.; Castello-Branco, G. A.; Garmestani, H.; Snyder, R. L.; Ribarik, G.; Ungar, T.: Evolution of dislocation density and character in hot rolled titanium determined by X-ray diffraction. Materials Characterization. 55 (2005) 66-74.

[103] Chatterjee, P.; Sen Gupta, S. P.: An X-ray diffraction study of nanocrystalline titanium prepared by high-energy vibrational ball milling. Appl. Surface Sci. 182 (2001) 372-376.

[104] Louër, D.; Auffredic, J. P.; Langford, J. I.; Ciosmak, D.; Niepce, J. C.: Thermodynamic study of the thermal decomposition of zinc hydroxinitrates. J. Appl. Cryst. 183 (1983) 16-23.

[105] Balzar, D.; Audebrand, N.; Daymond, M. R.; Fitch, A.; Hewat, A.; Langford, J. I.; Le Bail, A.; Louër, D.; Masson, O.; McCowan, C. N.; Popa, N. C.; Stephens, P. W.; Toby, B. H.: Size-strain line-broadening analysis of the ceria round-robin sample. J. Appl. Cryst. 37 (2004) 911-924.

[106] Baviera, P.; Harel, S.; Garem, H.; Grosbras, M.: Thermal stability and densification of nanostructured titanium carbide and graphite/nTiC composite. Mat. Sci. Forum. 343 (2000) 629634.

[107] Lin, J. D.; Duh, J. G.: The use of X-ray line profile analysis in the tetragonal to monoclinic phase transformation of ball milled, as-sintered and thermally aged zirconia powders. J. Mat. Sci. 32 (1997) 4901-4908. 
[108] Gubicza, J.; Szépvölgyi, J.; Mohai, I.; Zsoldos L.; Ungár, T.: Particle size distribution and the dislocation density determined by high resolution X-ray diffraction in nanocrystalline silicon nitride powders. Mat. Sci. Eng. A280 (2000) 263-269.

[109] Gubicza, J.; Szépvölgyi, J.; Mohai, I.; Ribárik, G.; Ungár, T.: The effect of heat-treatment on the grain-size of nanodisperse plasmathermal silicon nitride powder. J. Mater. Sci. 35 (2000) 3711-3717.

[110] Pantea, C.; Gubicza, J.; Ungár, T.; Voronin, G.; Zerda, T. W.: Dislocation density and graphitization of diamond crystals. Phys. Rev. B66 (2002) art. no. 094106.

[111] Pantea, C.; Gubicza, J.; Ungár, T.; Voronin, G. A.; Nam, N. H.; Zerda, T. W.: High pressure effect on dislocation density in nano-size diamond crystals. Diam. Relat. Mater. 13 (2004) $1753-1756$.

[112] Palosz, B.; Grzanka, E.; Pantea, C.; Zerda, T. W. Wang.; Gubicza, J.; Ungár, T.: Microstructure of nanocrystalline diamond powders studied by powder diffractometry. J. Appl. Phys. 97 (2005) 064316.

[113] Grzanka, E.; Palosz, B.; Gierlotka, S.; Pielaszek, R.; Bismayer, U.; Janik, J. F.; Wells, J. R.; Palosz, W.; Porsch, F.: Generation and relaxation of microstrains in GaN nanocrystals under extreme pressures. Acta Physica Polonica A102 (2002) 167-174.

[114] Palosz, B.; Grzanka, E.; Gierlotka, S.; Stelmakh, S.; Pielaszek, R.; Bismayer, U.; Neuefeind, J.; Weber, H.-P.; Proffen, Th.; Von Dreele, R.; Palosz, W.: Analysis of short and long range atomic order in nanocrystalline diamonds with application of powder diffractometry. Z. Kristallogr. 217 (2002) 497-509.

[115] Voronin, G. A.; Zerda, T. W.; Gubicza, J.; Ungár, T.; Dub, S. N.: Properties of nanostructured diamond-silicon carbide composites sintered by high pressure infiltration technique. J. Mater. Res. 19 (2004) 2703-2707.

[116] Gubicza, J.; Ungár, T.; Wang, Y.; Voronin, G.; Pantea, C.; Zerda, T. W.: Microstructure of diamond-SiC nanocomposites determined by X-ray line profile analysis. Diam. Relat. Mater. 15 (2006) 1452-1456.

[117] Warren, B. E.; Bodenstein, P.: The shape of two-dimensional carbon black reflections. Acta Cryst. 20 (1966) 602-605.

[118] Ungár, T.; Gubicza, J.; Ribárik, G.; Pantea, C.; Zerda, T. W.: Microstructure of carbon blacks determined by X-ray diffraction profile analysis. Carbon 40 (2001) 929-937.

[119] Ungár, T.; Gubicza, J.; Tichy, G.; Pantea C.; Zerda, T. W.: Size and shape of crystallites and internal stresses in carbon blacks. Composites Part A: Applied Science and manufacturing 36 (2005) 431-436.
[120] Palosz, B.; Gierlotka, S.; Stelmakh, S.; Pielaszek, R.; Zinn, P.; Winzenick, M.; Bismayer, U.; Boysen, H.: High-pressure hightemperature in situ diffraction studies of nanocrystalline ceramic materials at HASYLAB. J. Alloys and Compounds. 286 (1999) 184-194.

[121] Bertaut, E. F.: Raies de Debye-Scherrer et repartition des dimensions des domaines de Bragg dans les poudres polycristallines. Acta Cryst. 3 (1950) 14-18.

[122] Le Bail, A.; Louër, D.: Smoothing and validity of crystallitesize distributions from X-ray line-profile analysis. J. Appl. Cryst. 11 (1978) 50-55.

[123] van Berkum, J. G. M.; Vermuelen, A. C.; Delhez, R.; de Keijser, Th. H.; Mittemeijer, E. J.: Applicabilities of the WarrenAverbach analysis and an alternative analysis for separation of size and strain broadening. J. Appl. Cryst. 27 (1994) 345-357.

[124] Leoni, M.; Scardi, P.: Nanocrystalline domain size distributions from powder diffraction data. J. Appl. Cryst. 37 (2004) 629634.

[125] Audebrand, N.; Raite, S.; Louër, D.: The layer crystal structure of $\left[\mathrm{In}_{2}\left(\mathrm{C}_{2} \mathrm{O}_{4}\right)_{3}\left(\mathrm{H}_{2} \mathrm{O}\right)_{3}\right] \cdot 7 \mathrm{H}_{2} \mathrm{O}$ and microstructure of nanocrystalline $\operatorname{In}_{2} \mathrm{O}_{3}$ obtained from thermal decomposition. Solid State Sciences 5 (2003) 783-794.

[126] van Berkum, J. G. M.; Delhez, R.; de Keijser Th. H.; Mittemeijer, E. J.: Diffraction-Line Broadening due to Strain Fields in Materials; Fundamental Aspects and Methods of Analysis. Acta Cryst. A52 (1996) 730-747

[127] Ida, T.; Shimazaki, S.; Hibino, H.; Toraya, H.: Diffraction peak profiles from spherical crystallites with lognormal size distribution. J. Appl. Cryst. 36 (2003) 1107-1115.

[128] Zehetbauer, M. J.; Kohout, J.; Schafler, E.; Sachslehner, F.; Dubravina, A.: Plastic deformation of nickel under high hydrostatic pressure. J. Alloys Compd. 378 (2004) 329-334.

[129] Bolmaro, R. E.; Brokmeier, H. G.; Signorelli, J. W.; Fourtz, A.; Bertinetti, M. A.: Interaction between phases in Co-deforming two-phase materials: The role of dislocation arrangements. In: Diffraction analysis of the microstructure of materials (Eds. Mittemeijer, E. J., Scardi, P.) p. 391. Springer-Verlag. Berlin. Heidelberg, 2004.

[130] Hellmig, R. J.; Baik, S. C.; Bowen, J. R.; Estrin, Y.; Juul Jensen, D.; Kim, H. S.; Seo, M. H.: Evolution of mechanical and microstructural properties of ECAP deformed copper. In: Proc $2^{\text {nd }}$ International Conference on Nanomaterials by Severe Plas tic Deformation: Fundamentals - Processing - Applications. (Eds. M. J. Zehetbauer, R. Z. Valiev) pp. 420-425. J.Wiley VCH. Weinheim, 2004. 